

\section{Sumário}

Editorial

Mariela Morales Antoniazzi, Flávia Piovesan e Patrícia Perrone Campos Mello

I. Parte Geral

1. Constitucionalismo transformador: IUS Constitutionale Commune Na

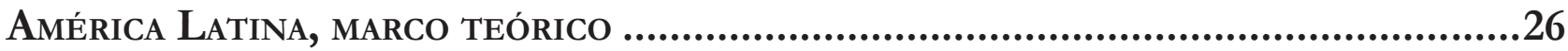

CONSTITUCIONALISMO TRANSFORMADOR INTERNACIONAL NA AMÉRICA LATINA......................28 Armin von Bogdandy e René Urueña

INTERDEPENDÊNCIA E INDIVISIBILIDADE DOS DIREITOS HUMANOS: UM NOVO OLHAR PARA A PANDEMIA DE Covid-19. .75

Flávia Piovesan e Mariela Morales Antoniazzi

DirEITOS HUMANOS EM TEMPOS DE EMERGÊNCIA: UMA PERSPECTIVA INTERAMERICANA COM especial foco na Defesa do Estado de Direito .95

Christine Binder

Monitoramento, PERSUASÃo E PROMOÇão do diálogo: QUAL O PAPEL DOS ORGANISMOS SUPRANACIONAIS DE DIREITOS HUMANOS NA IMPLEMENTAÇÃO DE DECISÕES INDIVIDUAIS?

Clara Sandoval, Philip Leach e Rachel Murray

REPENSANDO AS DERROGaÇÕES AOS TRATAdOS DE DiREITOS HUMANOS 142 Laurence R. Helfer

\section{ResiliÊNCIA DEMOCRÁtica: CoNTRIBUiçÕes do CONSTITUCIONALISMO}

TRANSFORMADOR CONTRA O RETROCESSO

A COMISSÃo INTERAMERICANA DE DiREITOS HUMANOS COMO WATCHDOG DEMOCRÁTICO: DESENVOLVENDO UM SISTEMA DE ALERTA PRECOCE CONTRA ATAQUES SISTÊMICOS...................169 Patrícia Perrone Campos Mello, Danuta Rafaela de Souza Calazans e Renata Helena Souza Batista de Azevedo Rudolf

Erosão democrática e a Corte InTeramericana de direitos humanos: o caso VENEZUELANO 196

Roberto Dias e Thomaz Fiterman Tedesco

ParticipaÇão política no Constitucionalismo latino-americano: uma ComparaÇão com o MODELO BRASILEIRO. 226 Júlio Grostein e Yuri Novais Magalhães 


\section{REFUNDAÇÃo DEMOCRÁtICA CONTRIBUIÇÕES DO CONSTITUCIONALISMO}

TRANSFORMADOR A UMA NOVA ORDEM CONSTITUCIONAL

LOS DERECHOS SOCIALES Y EL CONSTITUCIONALISMO TRANSFORMAdOR EN CHILE .251

Gonzalo Aguilar Cavallo

La aplicación del Derecho internacional de los derechos humanos en Chile: DIAGNÓSTICOS Y PROPUESTAS PARA UNA NUEVA CONSTITUCIÓN TRANSFORMADORA .275

Pietro Sferrazza Taibi, Daniela Méndez Royo e Eduardo Bofill Chávez

Diálogo Judicial no Ius COMMUNE LATINO-AMERICANO: COERÊNCIA, COESÃo E CONFORMAÇão CONSTITUCIONAL 314

Paulo Brasil Menezes

4. Diálogo ENTRE ORDENS INTERNACIONAIS E NACIONAIS: O CONSTITUCIONALISMO TRANSFORMADOR NA AMÉRICA LATINA

DIÁLOGO, INTERAMERICANIZACIÓN E IMPULSO TRANSFORMADOR: LOS FORMANTES TEÓRICOS DEL Ius Constitutionale Commune en América Latina ...............................................338 Mario Molina Hernández

O controle de convencionalidade pela Corte Interamericana de Direitos Humanos 364

Danilo Garnica Simini e José Blanes Sala

Controle legislativo DE CONVENCIONALIDADE DAS LEIS: A OPORTUNIDADE DE CONSTRUÇÃo do Ius Constitutionale Commune latino-americano pela Comissão de Constituição, Justiça e Cidadania da Câmara dos Deputados. .384

Ana Carolina Barbosa Pereira

A progressiva superaÇão da regulação do crime de desacato na América Latina: DIÁLOGOS ENTRE O DOMÉSTICO E O INTERNACIONAL .426 Luiz Guilherme Arcaro Conci e Melina Girardi Fachin

A interpretação do Sistema Interamericano de Direitos Humanos acerca da LIBERDADE DE EXPRESSÃo E A ADEQUAÇÃo MATERIAL DA LEI N. ${ }^{\circ} 13.834 / 2019$ 457 Elder Maia Goltzman e Mônica Teresa Costa Sousa

CAMINHOS LATINO-AMERICANOS A INSPIRAR A JURISDIÇÃo CONSTITUCIONAL BRASILEIRA NO DIÁLOGO MULTINÍVEL DO CONSTITUCIONALISMO REGIONAL TRANSFORMADOR .476 Rafael Osvaldo Machado Moura e Claudia Maria Barbosa

IUS CONSTITUTIONALE COMMUNE E DIREITO DE FAMÍlIA: UMA ANÁLISE HERMENÊUTICA DA jurisprudência da Corte Interamericana de Direitos Humanos e do Supremo Tribunal 
FEDERAL NA MATÉria

Felipe Frank e Lucas Miguel Gonçalves Bugalski

JusticiabilidAde DiRETA dos DiREITOS SOCIAIS NA CORTE INTERAMERICANA DE DIREITOS HUMANOS: MAIS UMA PEÇA NO QUEBRA-CABEÇA DO IUS CONSTITUTIONALE COMMUNE LATINOAMERICANO?.

Wellington Boigues Corbalan Tebar e Fernando de Brito Alves

5. DiÁlogo ENTRE ORDENS INTERNACIONAIS: O CONSTITUCIONALISMO TRANSFORMADOR ENTRE REGIÕES.

LA JURISPRUDENCIA EN EL DERECHO INTERNACIONAL GENERAL Y EL VALOR E IMPACTO DE LA jurisprudencia de la Corte Interamericana de Derechos Humanos y el Tribunal Europeo de Derechos Humanos..................................................................5545 Humberto Nogueira Alcalá

Diálogos À deriva: o Caso Lucien IKIli Rashidi c. República Unida da Tanzânia e outros e o esvaziamento da Corte Africana...........................................................568

Marcus Vinicius Porcaro Nunes Schubert e Catarina Mendes Valente Ramos

II. Parte especial

6. Povos indígenas E TRANSFORMAÇão

Hermenéuticas del derecho humano a la identidad CUltural EN La JURisprudencia INTERAMERICANA, UN ANÁLISIS COMPARADO A LA LUZ DEL ICCAL. .593 Juan Jorge Faundes e Paloma Buendía Molina

Ius Constitutionale Commune e O DiReito INdígena bRasileiro: os IMPaCtos da DeCisÃo do caso Povo Xukuru versus Brasil na jurisprudênCia e na administração pública NACIONAL

Flavianne Fernanda Bitencourt Nóbrega, Maria Eduarda Matos de Paffer e Anne Heloise Barbosa do Nascimento

Os PRECEDENTES dA CORTE INTERAMERICANA DE DIREITOS HUMANOS SOBRE TERRAS INDÍGENAS E A ADOÇÃO DA TEORIA DO INDIGENATO. 648

Eduardo Augusto Salomão Cambi, Elisângela Padilha e Pedro Gustavo Mantoan Rorato

7. Grupos VULNERÁVEIS E TRANSFORMAÇão

Ius Constitucionale Commune na América Latina: a Corte Interamericana de Direitos Humanos COMO INSTRUMENTO DE FIXAÇÃo DE STANDARDS PROTETIVOS AOS DiREITOS

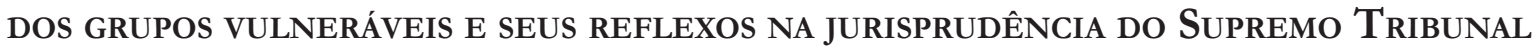
FEDERAL .666 Mônia Clarissa Hennig Leal e Eliziane Fardin de Vargas 
A eficácia da norma que ousou falar seu nome: os Princípios de Yogyakarta como potênCia densificadora do Ius Constitutionale Commune na América Latina .........687

Tiago Benício Trentini e Luiz Magno Bastos Jr

A Corte Interamericana de direitos humanos e a proteção dos direitos LGBTI: construindo um Ius Constitutionale Commune baseado na diversidade

João Pedro Rodrigues Nascimento, Tiago Fuchs Marino e Luciani Coimbra de Carvalho

LA VIOLENCIA INTRAFAMILIAR EN CONTEXTOS DE COVID-19: REALIDADES DEL AMPARO INSTITUCIONAL A SUJETOS DE ESPECIAL PROTECCIÓN EN ESCENARIOS DE EMERGÊNCIA .737 Víctor Julián Moreno Mosquera, John Fernando Restrepo Tamayo e Olga Cecilia Restrepo-Yepes

O caso Vélez loor vs. Panamá da Corte Interamericana de Direitos Humanos como PARADIGMA PARA A CONSTRUÇÃO DE PARÂMETROS MIGRATÓRIOS LATINO-AMERICANOS .757 Tatiana de A. F. R. Cardoso Squeff e Bianca Guimarães Silva

Direitos HUMANOS E ESTADO DE COISAS INCONSTITUCIONAL: O TRANSCONSTITUCIONALISMO LATINO-AMERICANO NA ADPF No 347 .783

Maiquel Ângelo Dezordi Wermuth e André Giovane de Castro

Trabalho escravo contemporâneo: as contribuições do diálogo ENTRE o Sistema InTERAMERICANo de Direitos Humanos E O Brasil PARA O FORTALECIMENTo dA Dignidade DO TRABALHADOR

Emerson Victor Hugo Costa de Sá, Sílvia Maria da Silveira Loureiro e Jamilly Izabela de Brito Silva

8. Direitos humanos, EMPRESAS e transformaÇão

DiÁlOgos MULTIATOR PARA IMPLEMENTAÇÃO DOS STANDARDS INTERAMERICANOS SOBRE Pandemia e Direitos Humanos

Ana Carolina Lopes Olsen e Anna Luisa Walter Santana

O ENVOLVIMENTO DE EMPRESAS EM VIOLAÇÕES DE DIREITOS HUMANOS E OS IMPACTOS DAS DECISÕES DA CORTE INTERAMERICANA

Patricia Almeida de Moraes e Marcella Oldenburg Almeida Britto

III. OUTRAS PERSPECTIVAS SOBRE TRANSFORMAÇÃO

Pluralismo jurídico e democracia comunitária: Discussões teóricas Sobre DESCOLONIZAÇÃo CONSTITUCIONAL NA BOLÍVIA

Débora Ferrazzo e Antonio Carlos Wolkmer

INTERCULTURALIDADE, PLURINACIONALIDADE E PLURALISMO NAS CONSTITUIÇÕES DO EQUADOR E DA BOLÍVIA: EXPOENTES PRINCIPIOLÓGICOS DO ESTADO PLURINACIONAL .897 Denise Tatiane Girardon dos Santos 
IUS COMMUNE: ENTRE O PLURALISMO JURISDICIONAL DIALÓGICO E A ADOÇÃO DE NORMAS ALTERATIVAS .

Ana Maria D'Ávila Lopes 


\title{
Hermenéuticas del derecho humano a la identidad cultural en la jurisprudencia interamericana, un análisis comparado a la luz del ICCAL*
}

\author{
Hermeneutics of the human right to cultural \\ identity in inter-american jurisprudence, a \\ comparative analysis in the light of the ICCAL
}

Juan Jorge Faundes**

Paloma Buendía Molina***

\section{Resumen}

Este trabajo busca demostrar, primero, que existe un derecho común latinoamericano que comprende el derecho humano a la identidad cultural, en la perspectiva del Ius Constitucionale Commune en América Latina (ICCAL). Segundo que, siguiendo el enfoque del ICCAL, al integrar una diversidad de fuentes, el derecho humano a la identidad cultural puede ser comprendido bajo diversos alcances normativos y ampara distintos titulares del derecho, lo cual tendrá consecuencias concretas en la hermenéutica de las sentencias nacionales de competencia constitucional que dialoguen con la jurisprudencia de la Corte Interamericana de Derechos Humanos (Corte IDH). Para ello, el trabajo presenta sintéticamente el ICCAL como marco teórico normativo que comprende el derecho humano a la identidad cultural; estudia el derecho fundamental a la identidad cultural, sus fuentes, alcances diversos y titulares, conforme se ha desarrollado progresivamente bajo la jurisprudencia de la Corte IDH; finalmente, revisa tres sentencias de tribunales superiores con competencia constitucional de Argentina, Chile y Brasil. Se concluye que el diálogo entre cortes internacionales y aquellas nacionales con competencia constitucional, puede contribuir a la protección de los derechos humanos de los pueblos indígenas y otros grupos vulnerables, asegurando su derecho humano a la identidad cultural, como presupuesto democrático. Metodológicamente se utiliza revisión bibliográfica, análisis de jurisprudencia y el método de derecho comparado.

Palabras clave: Derecho identidad cultural - Corte IDH - derecho a la vida - DESC - diálogo judicial

\section{Abstract}

This article seeks to demonstrate, first, that there is a common Latin American law that includes the human right to cultural identity, in the perspective of the Ius Constitucionale Commune in Latin America (ICCAL). Secondly, following the ICCAL approach, by integrating a diversity of sources, the hu- 
man right to cultural identity can be understood under different normative scopes and protects different right holders, which will have concrete consequences in the hermeneutics of national judgments of constitutional competence that dialogue with the jurisprudence of the Inter-American Court of Human Rights (I/A Court H.R). To this end, this paper synthetically presents ICCAL as a normative theoretical framework that comprises the human right to cultural identity; studies the fundamental right to cultural identity, its sources, diverse scopes and holders, as it has progressively developed under the jurisprudence of the IACHR Court; finally, reviews three judgments of superior courts with constitutional competence in Argentina, Chile and Brazil, seeking to identify whether or not this right has been taken up and, if so, with what scope and with respect to which holders. We concludes that the dialogue between international courts and national courts with constitutional competence, can contribute to the protection of the human rights of indigenous peoples and other vulnerable groups, ensuring their human right to cultural identity, as a democratic presupposition. Methodologically, a bibliographic review, jurisprudence analysis and the comparative law method were used.

Keywords: Cultural Identity Law - IACHR - right to life - social right - judicial dialogue

\section{Introducción}

Este trabajo presenta el derecho humano a la identidad cultural a la luz del Ius Constitucionale Commune en América Latina (ICCAL) y su perspectiva dialógica entre las sentencias de la Corte Interamericana de Derechos Humanos (Corte IDH) y las sentencias de tribunales nacionales de competencia constitucional, para determinar cómo puede contribuir a la protección de los derechos humanos de los pueblos indígenas y otros grupos vulnerables, asegurando su derecho humano a la identidad cultural, como presupuesto democrático.

En este marco, nuestra hipótesis plantea que, primero, en la perspectiva del Ius Constitucionale Commune en América Latina (ICCAL), existe un derecho común latinoamericano que comprende el derecho humano a la identidad cultural. Segundo, como consecuencia de ello, bajo el enfoque del ICCAL y siguiendo la jurisprudencia de la Corte IDH, la justificación hermenéutica del derecho humano a la identidad cultural integra una diversidad de fuentes de distinta naturaleza. Luego, tercero, el derecho humano a la identidad cultural puede ser comprendido bajo diversos alcances normativos y ampara distintos titulares del derecho. En particular, sostendremos que las fuentes referentes al derecho humano a la identidad cultural, lo justifican primariamente desde el derecho a la igualdad y no discriminación y luego: (i) lo vinculan, tanto con el derecho a la vida (en un sentido de sobrevivencia colectiva), interrelacionado con el derecho de propiedad, bajo la interpretación evolutiva que la Corte IDH hace para el amparo de los derechos de los pueblos indígenas; y, al mismo tiempo, (ii) se le comprende como derecho social (DESC), considerando sus correlativas obligaciones progresivas de cumplimiento efectivo, de alcance prestacional ${ }^{1}$. Cuarto, estas dos perspectivas tendrán correlativas consecuencias en la hermenéutica de las sentencias nacionales de competencia constitucional y en el diálogo que puedan establecer (o no) con la jurisprudencia de la Corte IDH, para la protección de los derechos humanos de grupos vulnerables como los pueblos indígenas, asegurando su derecho humano a la identidad cultural, como presupuesto democrático.

Para demostrar nuestro planteamiento, en este trabajo: (i) se revisa sintéticamente el ICCAL como marco teórico normativo que comprende el derecho humano a la identidad cultural; (ii) se define el derecho fundamental a la identidad cultural; (iii) se presenta su fundamentación desde sus fuentes y conforme se ha

\footnotetext{
En este aspecto nuestro estudio es solo descriptivo, en cuanto evidencia dos hermenéuticas diversas en la jurisprudencia interamericana sobre el derecho humano a la identidad cultural, teniendo claro los distintos efectos que pueden emanar de una y otra lectura. En especial, no abordamos aquí la debatida cuestión de la justiciabilidad de los derechos sociales. Entre muchos otros v. AGUILAR, Gonzalo (coord.). Derechos económicos, sociales y culturales en el Orden Constitucional Chileno. Santiago: Editorial Librotecnia, 2012. TORRES, Ricardo Lobo. A metamorfose do direitos sociais em mínimo existencial. In: SARLET, Ingo Wolfgang (org.). Direitos fundamentais sociais: estudos de direitos constitucional, internacional e comparado. Rio de Janeiro: Renovar, 2003.
} 
desarrollado progresivamente bajo la jurisprudencia de la Corte IDH; (iv) desde el marco descrito, se estudian, tres sentencias de tribunales superiores con competencia constitucional (de Argentina, Chile y Brasil), buscando identificar si se ha (o no) recogido este derecho y, en su caso, con qué alcance.

Metodológicamente se utiliza revisión bibliográfica, análisis de jurisprudencia y el método de derecho comparado, en la perspectiva dialógica propuesta por el mismo ICCAL.

Se concluye, primero, que un constitucionalismo transformador, bajo la perspectiva del ICCAL que propone un diálogo entre cortes internacionales y aquellas cortes nacionales con competencia constitucional, requiere un análisis caso a caso, diferenciando fuentes y efectos en concreto, ya que la idea de un "derecho común latinoamericano" no es estática ni cerrada. Corresponde a una hermenéutica abierta, dinámica, en que las fuentes y sus efectos, se articulan y reorganizan, generando marcos de protección en diversas dimensiones normativas, generalmente complementarias, y múltiples efectos, integrando, según las circunstancias, tanto derechos como el derecho a la vida (en el sentido colectivo de la sobrevivencia indígena como pueblos o colectivos humanos), en interrelación con el derecho a la propiedad (propiedad comunal) y la protección ambiental de los territorios en que habitan, entre otros aspectos. Segundo, que el derecho humano a la identidad cultural, comprendido a la luz del ICCAL, como un derecho común latinoamericano, constituye un "derecho matriz" de los derechos de los pueblos indígenas y un "filtro hermenéutico" en la labor jurisdiccional, contribuyendo así a la protección de los derechos humanos de grupos vulnerables como los pueblos indígenas y otros grupos tribales, lo cual, a su vez, fortalece la democracia en América Latina.

\section{El ius constitucionale commune como marco del derecho humano a la identidad cultural}

\subsection{EI ICCAL una nueva comprensión constitucional interamericana:}

El Ius Constitucionale Commune es una propuesta teórica y normativa enmarcada en el constitucionalismo transformador ${ }^{2}$. Se presenta como un proyecto que tiene por objetivo principal el cumplimento de las promesas centrales de las constituciones latinoamericanas, en relación a la protección y garantía de los derechos humanos, la democracia y el Estado de Derecho ${ }^{3}$. En particular busca ser un método aplicable por los estados que, al otorgar fuerza normativa a los preceptos constitucionales, contribuya a proteger las conquistas democráticas ya alcanzadas y los estándares consolidados en materia de derechos humanos ${ }^{4}$. Asume que los sistemas constitucionales latinoamericanos se insertan en una historia compartida de pobreza, desigualdad, exclusión, inseguridad, violencia y corrupción en cuyo origen la debilidad institucional es una causa relevante. Ello redunda en violaciones de derechos humanos que afectan la democracia y el Estado de Derecho. En este sentido, postula que para construir una verdadera democracia constitucional se deben superan tales deficiencias. Y, en este complejo escenario, se presenta una preocupación aún mayor hacia los denominados grupos vulnerables 5 .

\footnotetext{
2 KLARE, Karl E. Legal culture and transformative constitutionalism. South African Journal on Human Rights, v. 14, n. 1, p. 146-188, p. 150, jan. 1998. p. 150.

3 BOGDANDY, Armin von. Ius Constitucionale Commune na América Latina: uma reflexão sobre um Constitucionalismo Transformador. Revista de Direito Administrativo, Rio de janeiro, v. 269, maio/ago. 2015.

4 MELLO, Patrícia Perrone Campos. Constitucionalismo, transformação e resiliência democrática no Brasil: o Ius Constitucionale Commune na América Latina tem uma contribuição a oferecer?. Revista Brasileira de Políticas Públicas, Brasília, v. 9, n. 2 p.253-285, 2019. p. 275-276.

5 Entendemos por grupos vulnerables o minoritarios, indistintamente, a las colectividades de individuos que cumplen las siguientes condiciones: (i) participan de formas de vida usualmente diversas al patrón social y/o cultural dominante y, como resultado, son estigmatizados; (ii) tienen un status al de los demás ciudadanos con respecto al ejercicio de sus derechos (por lo general de facto), siendo objeto de prácticas discriminatorias; (iii) presentan dificultades que sus demandas sean consideradas por medio de la rep-
} 
El ICCAL plantea que el modelo de Estado constitucional permite racionalizar el poder e impone al Estado el respeto de la dignidad humana como un límite claro e innegociable.

Por otra parte, el ICCAL considera que las nuevas constituciones latinoamericanas, de un lado, pretenden avanzar en materia de derechos mediante transformaciones sociales profundas y de otro abundan las estructuras concentradas de poder que bloquean dichas transformaciones. Por ello plantea que se hace necesario un avance progresivo en los desafíos de democratización y cambio estructural, encaminado a un progresivo avance democrático y de fortalecimiento del Estado de Derecho.

En este marco, el ICCAL apuesta por una supra estatalidad, un diálogo pluralista entre ordenes nacionales e internacionales y una activa actuación de los operadores de justicia, específicamente de tribunales con competencia constitucional, en el conjunto de ideas que permiten la construcción de un cuerpo común o corpus iuris latinoamericano de los derechos humanos, como construcción regional de estándares en la materia siguiendo la jurisprudencia de la Corte IDH. Tales estándares son desarrollados a partir de la Convención Americana de Derechos Humanos (CADH) vinculada con el resto de instrumentos interamericanos, en articulación con las garantías aseguradas en las constituciones nacionales, junto a las interpretaciones y entendimientos que ha ido desarrollando progresivamente el Sistema Interamericano de Derechos Humanos (SIDH). Asimismo, el ICCAL prevé la ampliación de la jurisdicción constitucional, en un esfuerzo de empoderar las cortes con competencia constitucional y concretar estos estándares de derechos humanos, como base democrática y del Estado de Derecho. En consecuencia, la jurisprudencia interamericana dialoga con las decisiones de las cortes nacionales con competencia constitucional, como un entramado interconectado, conforme las cláusulas constitucionales de apertura del ordenamiento jurídico interno al Derecho Internacional de los derechos humanos ${ }^{6}$.

\subsection{Un "derecho común interamericano de los derechos humanos" a partir de la concepción de un "corpus iuris" de la Corte IDH (multiplicidad de fuentes / amplitud de efectos):}

El concepto de corpus iuris de derechos humanos que ha planteado la Corte IDH y que está en el núcleo de la propuesta del ICCAL, se ha descrito en el sentido que los sistemas de protección de derechos humanos constituyen un solo cuerpo jurídico articulado de garantía de estos derechos ${ }^{7}$. Se funda en la interacción o vínculo de retroalimentación nacional e internacional para la protección de los derechos humanos, configurando una suerte de nuevo orden público, resguardado bajo un proceso jurisdiccional de protección integral de carácter nacional e internacional. Este corpus iuris debe operar límite y marco normativo imperativo fijado mediante estándares internacionales, bajo el cual el respectivo sistema nacional debe guiar su conducta y cuyo incumplimiento compromete la responsabilidad internacional del Estado. De esta forma, la normativa internacional e interna de protección de los derechos humanos, opera como un solo orden jurídico consti-

resentación política (Legislativo y Ejecutivo); (iv) como consecuencia de los factores indicados, demandan acciones de protección específicas para su defensa y procurar su igualdad material. Grupos vulnerables y (demográfica o culturalmente) minoritarios, son asumidos bajo el mismo enfoque dado que se enfrentan a problemas similares y exigen cciones equivalentes para la protección y promoción de sus derechos. MELLO, Patrícia Perrone Campos; FAUNDES, Juan Jorge. Povos Indígenas e proteção da natureza: a caminho de um "giro hermenêutico ecocêntrico". Revista Brasileira de Políticas Públicas, Brasília, v. 10, n. 3, p. 222-251, 2020. p. 226

6 MELLO, Patricia Perrone Campos. Constitucionalismo, Tranformaçao e Reisiliencia Democrática no Brasil: o Ius Constitucionale Commune na America Latina tem uma contribuiçao a ofrecer? Revista Brasileira Políticas Públicas, Brasília, v. 9 n. 2. p. 253-254, 2019. Sobre la idea del diálogo judicial interamericano v. FERRER MAC-GREGOR, Eduardo. Diálogo judicial y control convencionalidad: aportes de la Corte Interamericana en la construcción de un IUS Constitucionale Commune Para América Latina (ICCAL). En: FERRER MAC-GREGOR, Eduardo (coord.). Derecho procesal constitucional transnacional. Interacción entre el derecho nacional y el derecho internacional. México: Editorial Porrúa, IMDPC. 2016. p. 277-294.

FAUNDES, Juan Jorge; CARMONA, Cristobal; SILVA, Pedro Pablo. La Corte IDH. Hermenéutica del derecho al medio ambiente sano, a la identidad cultural y a la consulta, a la luz de la sentencia "Lhaka Honhat (nuestra tierra) vs. Argentina" (2020). Revista Brasileira de Políticas Públicas, Brasilia, v. 10, n. 2 p. 635-666, 2020. p. 655-658. v. Caso Asociación Lhaka Honbat (nuestra tierra) vs Argentina (2020) v. párr. 198. 
tuido por "normas que no pueden ser modificadas por la voluntad unilateral de los estados".

Entonces, bajo lo que se ha llamado una hermenéutica abierta ${ }^{9}$, se trata de un enfoque que extiende la interpretación de los derechos humanos, expandiendo el alcance de la $\mathrm{CADH}$, articulándola con todo tipo de fuentes internacionales (vinculantes y no vinculantes), tales como: otros tratados internacionales de derechos humanos, decisiones de la CIDH y jurisprudencia de la Corte IDH, recomendaciones, observaciones y declaraciones de la Asamblea General de Naciones Unidas, de la Asamblea General de la Organización de Estados Americanos (OEA), informes y recomendaciones de diversos organismos especializados. Incluso, genéricamente, hace referencia al Tribunal Europeo de Derechos Humanos, al Sistema Africano de derechos Humanos ${ }^{10}$, otros instrumentos y se citan constituciones latinoamericanas o decisiones constitucionales comparadas ${ }^{11}$. De esta manera, la Corte, interrelaciona las fuentes principales del Derecho Internacional, invoca convenciones y Derecho Internacional consuetudinario, recurre a las fuentes complementarias, incluso instrumentos no vinculantes, para configurar y delimitar el contenido de las obligaciones contenidas en la CADH. Asimismo, la Corte IDH, bajo su doctrina de intérprete auténtica de la CADH, declara que estos estándares deben ser seguidos de forma obligatoria por los estados que han ratificado la CADH, bajo control de convencionalidad $\left.{ }^{12}\right)^{13}$.

En síntesis, bajo el objetivo final de la Corte de asegurar la protección más favorable a la persona, dejando en un segundo plano la ortodoxia formal de las fuentes del Derecho Internacional, impulsa una hermenéutica garantista y abierta a la interrelación de las fuentes internacionales, de otros sistemas regionales, más allá de que sean directamente vinculantes o no ${ }^{14}$.

Nuestro estudio considera diversos trabajos que afirman la existencia de un derecho común interameri-

\footnotetext{
8 NASH, Claudio. La Concepción de Derechos Fundamentales en Latinoamérica. Tendencias jurisprudenciales. Tesis (Doctorado). Universidad de Chile, Santiago, 2008. p. 311-312.

9 MORALES, Mariela. El estado abierto como objetivo del ius constitucionale commune. Aproximación desde el impacto de la Corte Interamericana de Derechos Humanos. En: BOGDANDY, Armin von, FIX-FIERRO, Héctor, MORALES, Mariela (ed.). Ius constitucionale comune en América Latina. Rasgos, potencialidades y desafíos. México: UNAM, MPI, IIDC, 2014. p. 265-299.

10 v. CORTE IDH. Caso comunidades indígenas miembros de la Asociación Lhaka Honhat (nuestra tierra) vs. Argentina. (2020), párr. 244 (nota 241).

11 CORTE IDH. Caso comunidades indígenas miembros de la Asociación Lhaka Honbat (nuestra tierra) vs. Argentina. (2020), párr. 206 (nota 195).

12 Entre otros, sobre "Control de convencionalidad” v. ALBANESE, Susana (coord.). El control de convencionalidad. Buenos Aires: Ediciones Ediar, 2008. FERRER MAC-GREGOR, Eduardo. Interpretación conforme y control difuso de convencionalidad el nuevo paradigma para el juez mexicano. En: CARBONELL, Miguel, SALAZAR, Pedro. Derechos Humanos: Un nuevo modelo constitucional. México: UNAM-IIJ, 2011. p. 339-429. FERRER MAC-GREGOR, Eduardo. Control de convencionalidad y buenas prácticas: sobre el diálogo judicial entre la Corte IDH y los tribunales nacionales. En: UGARTEMENDIA, Juan Ignacio; SAIZ, Alejandro; MORALES, Mariela. La jurisdicción constitucional en la tutela de los Derechos Fundamentales de la UE. Oñati: IVAP, MPI. 2017, p. 155-174. HENRÍQUEZ, Miriam; MORALES, Mariela. El control de convencionalidad: un balance comparado a 10 Años de Almonacid Arellano vs. Chile. Santiago: DER Ediciones. 2017. VARELLA, Marcelo; MONEBHUURRUN, Nitish; GONTIJO, André Pires. Proteção internacional dos direitos humanos. Rio de Janeiro: Editora Processo, 2019. p. 47-209. FERREIRA, Rafael Fonseca; ANADON, Celine Barreto. O diálogo hermenêutico e a pergunta adequada à aplicação dos tratados internacionais de direitos humanos no Brasil: caminhos para o processo de internacionalização da constituição. Brą̧ilian Journal of International Law, v. 12, n. 2, p. 175-192. 2015. VOLPINI, Carla Ribeiro; WANDERLEY JUNIOR, Silva Bruno. A responsabilidade internacional do Brasil em face do controle de convencionalidade em sede de direitos humanos: conflito de interpretação entre a jurisdição da Corte Interamericana de Direitos Humanos e o Supremo Tribunal Federal quanto a Lei de anistia. Brazilian Journal of International Law, v. 12 n. 2, p. 611-629, 2015. LEGALE, Siddharta. La Constitución Interamericana: Los 50 Años de la Convención Americana sobre Derechos Humanos en la Jurisprudencia de la Corte Interamericana de Derechos Humanos. En: COMITÉ Jurídico Interamericano Curso de Derecho Internacional XLVI 2019. Rio de Janeiro, Comité Jurídico Interamericano y el Departamento de Derecho Internacional de la Secretaría de Asuntos Jurídicos de la Organización de los Estados Americanos. 2019. p. 121-169.

13 Corte IDH. Caso comunidades indígenas miembros de la asociación Lhaka Honbat (nuestra tierra) vs. Argentina. (2020), párrs.202 (nota 191), párr. 208. v.

14 En el mismo sentido BURGORGUE-LARSEN, Laurence, se refiere al "Recurso a la «interpretación abierta»". BURGORGUELARSEN, Laurence. La Corte Interamericana de los Derechos Humanos como Tribunal constitucional. Em: MAUÉS, Antonio Moreira, MAGALHÃES, Breno Baía (org.). O controle de convencionalidade na América Latina: experiências comparadas. Rio de Janeiro: Lumen Juris, 2018. p. 22-31.
} 
cano relativo a los pueblos indígenas y otros grupos tradicionales ${ }^{15}$. En particular que abordan la protección del derecho a la identidad cultural de los pueblos indígenas y otros grupos tradicionales, como categoría autónoma y o desde el concepto de derecho a la "vida digna"16 o del derecho "a la integridad personal"17. Asimismo, que sostienen: (i) la especial titularidad como sujetos de derechos colectivos de los pueblos indígenas asociados a sus derechos territoriales y a los recursos naturales; y (ii) el "reconocimiento de la diversidad cultural y de los derechos económicos, sociales y culturales que le son asociados" en relación con los "recursos naturales necesarios tanto para su subsistencia y supervivencia física como cultural"18.

\section{El derecho humano a la identidad cultural: una definición}

Podemos definir el derecho humano a la identidad cultural como el derecho de todo colectivo étnico-cultural y de sus integrantes a conservar su propia cultura, su patrimonio cultural tangible o intangible, su memoria histórica y su presente y a ser reconocidos como diferente en sus relaciones con otros grupos de la sociedad. Este derecho comprende el derecho a que se respeten sus conocimientos, creencias, artes, moral, religión, normas y prácticas; y el derecho de sus miembros a pertenecer a una cultura, a no ser forzado a pertenecer a una cultura diferente o a no ser asimilado por aquella ${ }^{19}$.

Se trata de un derecho de naturaleza colectiva y o individual, dado que su titularidad pertenece a pueblos indígenas, sus comunidades u otros grupos culturales y a sus respectivos integrantes. En relación con las obligaciones del Estado, por una parte, considera el respeto, valor y protección de la identidad y cultura de un grupo, inclusiva de todos los bienes materiales e inmateriales que la componen, frente al mismo Estado o a terceros; por otra, exige que los derechos sean interpretados a la luz de la propia identidad cultural, la cosmovisión o universo existencial de estos grupos.

Como veremos, el derecho humano a la identidad cultural se configura desde fuentes de Derecho Internacional general, regional y de aquellas referentes a minorías u otros grupos vulnerables y sus derechos culturales. En el ámbito interamericano su desarrollo progresivo obedece en gran medida a los esfuerzos de la Corte IDH.

\footnotetext{
15 ESTUPIÑAN, Rosmelin; IBÁÑEZ, Juana María. La jurisprudencia de la Corte Interamericana de Derechos Humanos en materia de pueblos indígenas y tribales. París: Universidad de París. Grupo de Estudios en Derecho Internacional y Latinoamericano de la Sorbona. 2014. p. 325-326. MORALES, Mariela. La vulnerabilidad como principio transnacional. Aportes de la CORTE IDH a la luz del IUS CONSTITUCIONALE COMMUNE democrático. En: FERRER MAC-GREGOR, Eduardo (coord.). Derecho procesal constitucional transnacional. Interacción entre el derecho nacional y el derecho internacional. México: Editorial Porrúa, IMDPC, 2016. p. 295-334. p. 323-326.

16 CALDERÓN, Jorge. Avances, aproximaciones y desafíos emergentes en el reconocimiento de los derechos colectivos de los pueblos indígenas y tribales en la jurisprudencia de la Corte Interamericana de Derechos Humano. En: BOGDANDY, Armin von; MORALES, Mariela; FERRER MAC-GREGOR, Eduardo (ed.). Construcción de un ius constitucionale commune en América Latina. México: UNAM, MPI, CORTE IDH, 2016. p. 105-107.

17 BÁEZ, N. Lima. La protección de la identidad cultural de los pueblos indígenas a través del derecho a la integridad personal. Revista electrónica methodos, n. 1, p. 23-45, 2011.

18 AGUILAR, Gonzalo. Emergencia de un derecho constitucional común en materia de pueblos indígenas. En: BOGDANDY, Armin von; FERRER MAC-GREGOR, Eduardo, MORALES-ANZIONATTI, Mariela, 2010 (coord.). La justicia constitucional y su internacionalización. ¿Hacia un Ius Constitucionale Commune en América Latina? México: UNAM, MPI, IIADC. 2010. Tomo II. p. 3-84. p. 16-20.

19 FAUNDES, Juan Jorge; RAMÍREZ, Silvina (ed). Derecho fundamental a la identidad cultural, abordajes plurales desde América Latina. Santiago: RIL, Universidad Autónoma de Chile, 2020. p. 28. También v. DEL CARPIO RODRÍGUEZ, Columba. Pluralismo jurídico. Derecho humano a la identidad cultural y globalización. Pamplona: CIVITAS, Thomson Reuters, 2014. p. 48-49. RUIZ CHIRIBOGA, Oswaldo. El derecho a la identidad cultural de los pueblos indígenas y las minorías nacionales: una mirada desde el sistema interamericano. Revista Internacional de Derechos Humanos, v. 5, n. 3, p. 43-69, 2006.
} 


\section{Justificación del el derecho humano a la identidad cultural desde sus fuentes ${ }^{20}$.}

La Declaración Universal de Derechos Humanos en su artículo 22 dispone que "Toda persona, como miembro de la sociedad, tiene derecho a obtener... la satisfacción de los derechos económicos, sociales y culturales, indispensables a su dignidad y al libre desarrollo de su personalidad" y en su artículo 27 agrega que toda persona "tiene derecho de participar libremente en la vida cultural de la comunidad...". Luego, el Pacto Internacional de Derechos Económicos, Sociales y Culturales (PIDCP), en armonía con la Declaración Universal de Derechos Humanos, en su artículo 1 prescribe que los pueblos "establecen libremente su condición política y proveen asimismo a su desarrollo económico, social y cultural". Asimismo, en el artículo 15, No1 del Pacto Internacional de Derechos Económicos, Sociales y Culturales (PIDESC), establece que "Los Estados Partes en el presente Pacto reconocen el derecho de toda persona a [a] Participar en la vida cultural...”. Por su parte, el artículo 27 del PIDCP prescribe que:

En los Estados en que existan minorías étnicas, religiosas o lingüísticas, no se negará a las personas que pertenezcan a dichas minorías el derecho que les corresponde, en común con los demás miembros de su grupo, a disfrutar de su propia cultura, a profesar y practicar su propia religión y a emplear su propio idioma $^{21}$.

En este marco, organismos especializados de derechos humanos fundamentan los derechos culturales de minorías incluyendo en ellas a los pueblos indígenas y tribales en el artículo 1 común del PDCP y del PIDESC, en el artículo 27 del PDCP y en el artículo 15 del PIDESC ${ }^{22}$. Estos instrumentos de derechos humanos, en su conjunto y considerando su respectiva naturaleza y alcance normativo, permiten plantear una primera configuración del derecho humano a la identidad cultural en el marco del Derecho Internacional General.

De esta forma, el derecho humano a la identidad cultural se ha ido configurando como derecho estrechamente relacionado con derechos como la libre determinación de los pueblos, la igualdad y no discriminación, entre otros, que contienen un mandato de protección al Estado de los pueblos y grupos minoritarios que lo integran, generando una nueva comprensión más compleja del principio de igualdad centrada en el valor de la diferencia y la diversidad cultural como valor de las sociedades democráticas (bajo el reconocimiento de la diversidad sexual, jurídica, cultural, étnica, religiosa, etc.) que ha desplazado la idea de la mera igualdad formal antes preponderante.

Entonces, a partir de las fuentes descritas, podemos observar tres enfoques utilizados para justificar el derecho humano a la identidad cultural en el Derecho Internacional. El primero, basal y genérico, de protección de la identidad étnica y cultural, en el marco del derecho a la no discriminación de las minorías. $\mathrm{Y}$ otros dos que ya refieren expresamente a un "derecho a la identidad cultural". En estas otras dos perspectivas se centrará nuestro estudio: (i) como un derecho humano autónomo que en su visión más intensa se vincula con el derecho a la vida (en sentido de la sobrevivencia de los pueblos indígenas y otros grupos

\footnotetext{
20 Para el estudio del desarrollo progresivo del derecho humano a la identidad cultural en las fuentes del Derecho Internacional de los Derechos Humanos v. OLIVARES, Alberto. El Derecho a la identidad cultural. En: AGUILAR, Gonzalo (coord.). Nuevos derechos para una nueva Constitución. Valencia: Tirant Lo Blanch. 2019. p, 175-190. FAUNDES, Juan Jorge. El derecho fundamental a la identidad cultural de los pueblos indígenas: un derecho matriz y filtro hermenéutico para las constituciones de América Latina: la justificación. Revista Brasileira de Políticas Públicas, Brasília, v. 10, n. 2, p. 635-666, 2020.

21 Este artículo, en su génesis no fue ideado para la protección de grupos o minorías, sin embargo, hoy se asocia a los de derechos de los pueblos indígenas. AYLWIN, José; MEZA-LOPEHANDÍA, Matías; YAÑEZ, Nancy. Los pueblos indigenas y el derecho. Santiago: LOM, 2013. p. 453-454.

22 ONU: Comité de Derechos Económicos, Sociales y Culturales (CESCR), Observación general No 21, Derecho de toda persona a participar en la vida cultural (artículo 15, párrafo 1 a), del Pacto Internacional de Derechos Económicos, Sociales y Culturas),), párr. 36. Fecha 21 Diciembre 2009, E/C.12/GC/21, disponible en esta dirección: https://www.refworld.org.es/docid/4ed35beb2. html [Accesado el 27 Mayo 2021].
} 
tradicionales); (ii) como derechos social y cultural (DESC), integrante del "derecho a la participación en la vida cultural".

Así, en el primer marco general, vinculado a la no discriminación, para la justificación del derecho humano a la identidad cultural, encontramos la Convención Internacional sobre la Eliminación de todas las Formas de Discriminación Racial (1969) artículo 1 y 5 y complementariamente la "Declaración sobre la Raza y los Prejuicios Raciales" (1978) que en su artículo 5 señala que "deben respetar el derecho de todos los grupos humanos a la identidad cultural y al desarrollo de su propia vida cultural en el marco nacional e internacional... a cada grupo el decidir con toda libertad si desea mantener y, llegado el caso, adaptar o enriquecer los valores que considere esenciales para su identidad".

Conjuntamente también están los instrumentos que consideran en específico la protección de derechos culturales y la identidad cultural, tales como: la "Convención sobre la protección del patrimonio mundial, cultural y natural” (1972), la "Convención para la salvaguardia del patrimonio cultural inmaterial” (2003) y la “Convención sobre la Protección y Promoción de la Diversidad de Expresiones Culturales” (2005).

La "Convención para la salvaguardia del patrimonio cultural inmaterial" (2003) dispone la obligación de respetar el "patrimonio cultural inmaterial de las comunidades, grupos e individuos..." (artículo 1. b.), asegurando la protección del derecho fundamental a la identidad cultural. La "Convención sobre la Protección y Promoción de la Diversidad de Expresiones Culturales” (2005) reiteró la comprensión de la UNESCO sobre la diversidad cultural como "patrimonio común de la bumanidad" que:

... sólo puede ser protegida y promovida mediante la salvaguardia de los derechos humanos [... ] la diversidad cultural, tal y como prospera en un marco de democracia, tolerancia, justicia social y respeto mutuo entre los pueblos y las culturas, es indispensable para la paz y la seguridad en el plano local, nacional e internacional $[\ldots]$ que la cultura adquiere formas diversas a través del tiempo y el espacio y que esta diversidad se manifiesta en la originalidad y la pluralidad de las identidades... de los pueblos y sociedades que forman la humanidad... ${ }^{23}$.

En el mismo sentido, sobre la relación entre protección de la diversidad cultural y los derechos humanos, se pueden destacar dos de sus principios rectores: (i) el "Principio de respeto de los derechos humanos y las libertades fundamentales", conforme el cual sólo se podrá proteger y promover la diversidad cultural si se garantizan los restantes derechos humanos y las libertades fundamentales (artículo 2.1.); el "Principio de igual dignidad y respeto de todas las culturas", que contempla la protección y promoción de la diversidad de las expresiones culturales y la igual dignidad de todas las culturas y el respeto de ellas, "comprendidas las culturas de las personas pertenecientes a minorías y las de los pueblos autóctonos" (artículo 2.3.). Asimismo, la "Declaración sobre los Derechos de las Personas pertenecientes a minorías nacionales o étnicas, religiosas y lingüísticas" (1992) y la "Declaración Universal de la Unesco sobre la identidad cultural" (2001), han sido centrales en la consolidación del contenido de las Convenciones de la UNESCO que les sucedieron. La Declaración de 1992 significó un tránsito desde el reconocimiento genérico de la diversidad cultural por parte del Estado, hacia el reconocimiento del derecho a la identidad cultural, propiamente tal, como un derecho humano asegurado por el Derecho Internacional de los derechos humanos ${ }^{24}$. Esta Declaración establece el deber del Estado de protección de la identidad cultural de las minorías y de fomentar las condiciones para la promoción de este derecho, lo que pasará ser parte del contenido normativo del derecho humano a la identidad cultural en los instrumentos posteriores. Finalmente, otros instrumentos concurrentes son: la "Declaración de los Principios de la Cooperación Cultural Internacional" (1966); la "Recomendación sobre el Intercambio Internacional de Bienes Culturales" (1976); y la "Recomendación sobre la Salvaguardia de la Cultura Tradicional y Popular" (1989). Estas fuentes, principales y auxiliares.

En el caso del SIDH, la Carta de la OEA, como instrumento base regional y el "Protocolo Adicional de

23 Extracto Preámbulo de la Convención sobre la Protección y Promoción de la Diversidad de Expresiones Culturales de 2005.

24 DEL CARPIO, Columba. Pluralismo Jurídico, derecho bumano a la identidad cultural y globalización. Navarra: CIVITAS, Thomson Reuters, 2014. p. 70. 
la Convención Americana sobre Derechos Humanos en materia de Derechos Económicos, Sociales y Culturales" o "Protocolo de San Salvador" (1988), aseguran los derechos económicos sociales y culturales, más el derecho al medio ambiente sano para los pueblos indígenas, sus comunidades e integrantes, interconectados con el derecho a la identidad cultural y otros derechos. En este sentido señala que los Estados partes:

“... reconocen el derecho de toda persona a: participar en la vida cultural y artística de la comunidad" (artículo 14.1.a);

“... los Estados partes en el presente Protocolo deberán adoptar las medidas necesarias para asegurar el pleno ejercicio de este derecho” (artículo 14.2).

Entonces, en el ámbito regional, el artículo 14 del Protocolo constituye una fuente del derecho humano a la identidad cultural al reconocer el derecho de toda persona a participar en la vida cultural de la comunidad, junto a la obligación específica de los estados de adoptar las medidas necesarias para asegurar el pleno ejercicio del derecho.

También debe contemplarse como fuente del derecho humano a la identidad cultural la Declaración Americana de los Derechos y Deberes del Hombre de 1948 que dispone que "Toda persona tiene el derecho de participar en la vida cultural de la comunidad..." (Artículo XIII). Esta declaración bajo la hermenéutica de la Corte IDH constituye un instrumento básico enlazada a la Carta de la OEA y la CADH.

Por otra parte, el derecho humano a la identidad cultural se configura desde los tratados que aseguran el derecho a la identidad cultural de los pueblos indígenas y otros grupos (tribales y o afrodescendientes), como el Convenio 169 OIT sobre Pueblos Indígenas y Tribales en Países Independientes, de la Organización Internacional del Trabajo de 1989 (Convenio 169 de la OIT) y el artículo 8 j del Convenio sobre Diversidad Biológica (1992). El Convenio 169 de la OIT fundamenta y protege el derecho humano a la identidad cultural al establecer la obligación de respeto y garantía de "su integridad" (artículo 2.1), considerando la promoción de la plena "efectividad de los derechos sociales, económicos y culturales de esos pueblos, respetando su identidad social y cultural, sus costumbres y tradiciones, y sus instituciones" (artículo 2.2b). También señala que "Deberán adoptarse las medidas especiales que se precisen para salvaguardar las personas, las instituciones, los bienes, el trabajo, las culturas y el medio ambiente de los pueblos interesados" (artículo 4.1) y que "deberán reconocerse y protegerse los valores y prácticas sociales, culturales, religiosos y espirituales propios de dichos pueblos y deberá tomarse debidamente en consideración la índole de los problemas que se les plantean tanto colectiva como individualmente" (artículo 5 a)). Asimismo, conforme al artículo 7.1 vincula el derecho a la libre determinación con el derecho humano a la identidad cultural, mientras en los artículos 8, 9 y 10, entre otros, desarrolla un conjunto de disposiciones que se articulan con las diversas dimensiones del derecho humano a la identidad cultural, en base al reconocimiento de las costumbres, prácticas, instituciones, derecho consuetudinario y sistemas propios de solución de conflictos de los pueblos indígenas. Por último, en el artículo 13.1 del Convenio 169 de la OIT establece que en la aplicación de este tratado internacional los gobiernos "deberán respetar la importancia especial que para las culturas y valores espirituales de los pueblos interesados reviste su relación con las tierras o territorios [y] en particular, los aspectos colectivos de esa relación" (artículo 13.1.).

En estrecha vinculación con el marco precedente, el Convenio sobre Diversidad Biológica (1992) resguarda "los conocimientos, las innovaciones y las prácticas de las comunidades indígenas y locales que entrañen estilos tradicionales de vida pertinentes para la conservación y la utilización sostenible de la diversidad biológica" (artículo 8.j)) Esta disposición protege la dimensión socio cultural del medio natural (y el concepto de "patrimonio natural" de los Convenios de la UNESCO). Luego, respecto al objeto de nuestro estudio, está centrado en la protección de los conocimientos tradicionales indígenas que integran su patrimonio e identidad cultural.

Conjuntamente, en 2007 se aprobó la Declaración de las Naciones Unidas sobre los Derechos de los Pueblos Indígenas (DNUDPI) que recoge y protege diversas expresiones y alcances del derecho a la identi- 
dad cultural. Por ejemplo, asegura el derecho a la identidad como un derecho humano de naturaleza colectiva, expresando que la identidad se forja en el sentido de pertenencia que se tiene a un grupo humano, del que como individuo se siente parte y que se sustenta en el comportamiento de un colectivo o comunidad humana. La DNUDPI ampara el derecho a la identidad cultural cuando dispone, entre otros pasajes, que "Los pueblos y los individuos indígenas tienen derecho a pertenecer a una comunidad o nación indígena, de conformidad con las tradiciones y costumbres de la comunidad o nación de que se trate" (art. 9); y cuando señala que "Los pueblos indígenas tienen derecho a practicar y revitalizar sus tradiciones y costumbres culturales. Ello incluye el derecho a mantener, proteger y desarrollar las manifestaciones pasadas, presentes y futuras de sus culturas, como lugares arqueológicos e históricos, objetos, diseños, ceremonias, tecnologías, artes visuales e interpretativas y literaturas" (art. 11.1) y que "Los pueblos indígenas tienen derecho a determinar su propia identidad o pertenencia conforme a sus costumbres y tradiciones". Como correlato, en el ámbito regional americano, la OEA en 2016 aprobó la "Declaración Americana sobre los derechos de los pueblos indígenas" (DADPI), que considera el derecho a la identidad cultural como un valor transversal (artículos XIII a XIX).

Finalmente, la CADH, como instrumento base del SIDH, no considera de forma textual el derecho a la identidad cultural. Pero ha sido la Corte IDH la que ha establecido que la Convención Americana ampara el derecho humano a la identidad cultural de los pueblos indígenas, sus comunidades, otros grupos minoritarios tradicionales y sus respectivos integrantes ${ }^{25}$. Por esta razón estudiaremos la CADH directamente desde la perspectiva desarrollada por la Corte IDH en su jurisprudencia.

\section{El derecho humano a la identidad cultural en la jurisprudencia de la corte IDH ${ }^{26}$}

\subsection{Dos hermenéuticas para un derecho:}

La Corte IDH no ha fundamentado el derecho humano a la identidad cultural de manera uniforme. A lo menos, lo ha reconocido bajo dos líneas de argumentación. Por una parte, la Corte lo ha entendido como derecho de naturaleza colectiva que sustenta la sobrevivencia de los pueblos indígenas, conforme los artículos 1.1, 2, 29.b, 63, 21, 24, 3, 4, 5, 11, 12, 23, 13, 16, 17, de la CADH, invocando adicionalmente el Convenio No169 de la OIT. Por otra, lo comprende como un derecho de carácter social y de desarrollo progresivo (DESC), a la luz del artículo 26 de la CADH, en relación a los artículos 1.1 y 2, 21 y 24 de la misma Convención. Así, vinculando la CADH con un conjunto de otros instrumentos de diversa naturaleza como los previamente sintetizados, en particular el Protocolo de San Salvador, ha establecido que la CADH reconoce el derecho a la participación en la vida cultural y, dentro de él, el derecho a la identidad cultural ${ }^{27}$.

La argumentación de la Corte relativa al derecho humano a la identidad cultural, en primer término, para los dos enfoques descritos, tiene como base una hermenéutica extensiva, evolutiva y sistemática de la

\footnotetext{
25 Entre otros v. CORTE IDH. Caso comunidades indígenas miembros de la asociación Lhaka Honhat (nuestra tierra) vs. Argentina, sentencia de 6 de febrero de 2020, fondo, reparaciones y costas, párr. 231, Nota 233.

26 En este trabajo no abordamos la extensa jurisprudencia de la Corte IDH en torno al desarrollo evolutivo del Derecho Humano a la identidad cultural, solo nos centramos en el debate planteado sobre las dos hermenéuticas que surgen de sus decisiones. Sobre el estudio de tal jurisprudencia v. FAUNDES, Juan Jorge; VALLEJOS, Liz. El derecho fundamental a la identidad cultural de los pueblos indígenas, titulares, naturaleza, contenido y alcances, desde la jurisprudencia de la Corte Interamericana de Derechos Humanos. Em: FAUNDES Juan Jorge; RAMÍREZ Silvina (ed.). Derecho fundamental a la identidad cultural, abordajes plurales desde América Latina. Santiago: RIL, Universidad Autónoma de Chile, 2020. p. 107-144. También v. supra notas 17-18.

27 CORTE IDH. Caso comunidades indígenas miembros de la asociación Lhaka Honhat (nuestra tierra) vs. Argentina, sentencia de 6 de febrero de 2020 (fondo, reparaciones y costas), párr. 231, Nota 233.
} 
CADH que se basa en el artículo 1, que contempla la "Obligación de Respetar los Derechos" y el artículo 2, que asegura el "Deber de Adoptar Disposiciones de Derecho Interno", en relación al artículo 29 b), que fundamenta la interpretación evolutiva ${ }^{28}$, y el artículo 63, que contempla la obligación de reparación.

Luego, considerado este derecho como presupuesto de la sobrevivencia colectiva, el principal argumento (presente en la mayor parte de las decisiones de la Corte recaídas sobre derechos de los pueblos indígenas y otros grupos tribales), es desarrollado a partir de los efectos extensivos otorgados a la protección de la propiedad (artículo $21 \mathrm{CADH}$ ), más una interpretación también amplia y compleja del derecho a la igualdad y la no discriminación (artículo $24 \mathrm{CADH}$ ). Conjuntamente, la Corte IDH ha vinculado la protección de las tierras indígenas y sus recursos naturales (artículo 21) con los derechos a la vida (artículo 4 CADH) y a la integridad personal (artículo $5 \mathrm{CADH})$.

Mientras, desde el enfoque relativo a los derechos sociales, la Corte IDH ha formulado una fundamentación en base al artículo 26 de la $\mathrm{CADH}^{29}$ para amparar un conjunto de derechos, interdependientes, de carácter económico, social y cultural, y al medio ambiente (DESCA), tales como: el derecho humano al medio ambiente sano, el derecho humano al agua y saneamiento, el derecho a la alimentación adecuada y el propio derecho humano a la identidad cultural (considerándolo como integrante del derecho a la participación en la vida cultural). La Corte IDH para aplicar el artículo 26 de la CADH y reconocer los derechos en referencia, relacionó esta disposición con las obligaciones que emanan del Protocolo de San Salvador y un conjunto de instrumentos de Derecho Internacional de diversa naturaleza ${ }^{30}$, fijando, asimismo, el estándar de cumplimento sobre la base del principio de la efectividad de las medidas. En particular, la Corte IDH relacionó el artículo 26 de la CADH con los artículos 30, 31, 33 y 34 de la Carta de la OEA, considerando, entre otros aspectos, la obligación dispuesta en ellos de alcanzar el "desarrollo integral [...] de sus pueblos"31.

Como hemos anunciado, a la luz de las fuentes sintetizadas, la jurisprudencia de la Corte IDH desarrolla el derecho humano a la identidad cultural desde otras dos grandes dimensiones: (i) como derecho humano autónomo, vinculado a la vida, la integridad personal y la propiedad, entre otros; y (ii) como integrante del derecho a la participación en la vida cultural (DESC o DESCA).

\subsection{Fundamentación desde los derechos a la vida, la propiedad y la no discriminación:}

En los casos de la Comunidad indígena Yakye Axa vs. Paraguay (2005 y 2006), de la Comunidad Indígena Sawhoyamaxa vs. Paraguay (2006) y el Caso de la Comunidad Indígena Xákmok Kásek vs. Paraguay (2010), los demandantes afirmaron que su derecho de propiedad que no había sido garantizado por el Estado de Paraguay. Señalaron que, pese a que en cada caso se encontraba su solicitud de reivindicación territorial en tramitación (desde 1993, 1991 y 1990, respectivamente), no había sido resuelta satisfactoriamente. Ello generó la imposibilidad estas comunidades y sus miembros de acceder a la propiedad y posesión de su territorio, lo que las mantenía en estado de vulnerabilidad alimenticia, médica y sanitaria, amenazando de forma continua su supervivencia y la propia integridad de sus integrantes. ${ }^{32}$

\footnotetext{
28 FAUNDES, Juan Jorge. Interpretación evolutiva de los derechos humanos. En: ÁLVAREZ, Mario Ledesma, CIPPITANI, Roberto (coord.). Diccionario Analítico de Derechos Humanos e Integración Jurídica. Roma $\square$ Perugia $\square$ México: ISEG, 2013. p. 325-332.

29 CADH Cap. III Derechos Económicos, Sociales y Culturales. Art 26. Desarrollo Progresivo:

"Los Estados Partes se comprometen a adoptar providencias, tanto a nivel interno como mediante la cooperación internacional, especialmente económica y técnica, para lograr progresivamente la plena efectividad de los derechos que se derivan de las normas económicas, sociales y sobre educación, ciencia y cultura, contenidas en la Carta de la Organización de los Estados Americanos "[...]".

30 La Corte IDH refiere así a un "corpus iuris internacional". Caso Asociación Lhaka Honhat (nuestra tierra) vs Argentina (2020) v. párr..198.

31 CORTE IDH. Caso comunidades indígenas miembros de la asociación Lhaka Honhat (nuestra tierra) vs. Argentina, sentencia de 6 de febrero de 2020 (fondo, reparaciones y costas), párrs. 195, 2020.

32 CORTE IDH. Caso Comunidad Indígena Yakye Axa vs. Paraguay, 17 junio 2005. párr.2.
} 
Dijo la Corte en su sentencia de la Comunidad Yakye Axa vs. Paraguay (fondo 2005):

"Al analizar el contenido y alcance del artículo 21 de la Convención en el presente caso, la Corte tomará en cuenta... la significación especial de la propiedad comunal de las tierras ancestrales para los pueblos indígenas, inclusive para preservar su identidad cultural y trasmitirla a las generaciones futuras" ${ }^{\prime 3}$.

"Al desconocerse el derecho ancestral de los miembros de las comunidades indígenas sobre sus territorios, se podría estar afectando otros derechos básicos, como el derecho a la identidad cultural y la supervivencia misma de las comunidades indígenas y sus miembros" ${ }^{\prime 34}$.

Asimismo, en el Caso de la Comunidad indígena Yakye Axa vs. Paraguay (fondo 2005) ${ }^{35}$, la Corte IDH expresó que, para garantizar efectivamente los derechos a las comunidades indígenas, "los Estados deben tomar en consideración las características propias que diferencian a los miembros de los pueblos indígenas de la población en general y que conforman su identidad cultural" 36 . En este sentido declaró que "la cultura de los miembros de las comunidades indígenas corresponde a una forma de vida particular de ser, ver y actuar en el mundo" que se conforma "a partir de su estrecha relación con sus territorios tradicionales y los recursos que allí se encuentran... porque constituyen un elemento integrante de su cosmovisión, religiosidad y, por ende, de su identidad cultural" ${ }^{37}$. Agregó que el Estado:

“... ha lesionado el profundo vínculo que existe entre la identidad de la Comunidad y de sus miembros y su tierra ancestral. El Estado ha insistido en negar la identidad de la Comunidad Yakye Axa y sus miembros, y lo ha hecho tratando de diluirla... El Estado ha negado también la historia y la memoria de la Comunidad, así como el esencial sentido que para su cosmogonía y la de sus miembros tiene la relación con su tierra ancestral y su territorio. De esta forma, el Estado paraguayo ha vulnerado el derecho de la Comunidad Yakye Axa y de sus miembros a tener una identidad y una cosmogonía propias y, en esa medida, ha violado en perjuicio de los miembros de la Comunidad su derecho a la vida." ${ }^{38}$

“... Las afectaciones especiales del derecho a la salud, e íntimamente vinculadas con él, las del derecho a la alimentación y el acceso al agua limpia impactan de manera aguda el derecho a una existencia digna y las condiciones básicas para el ejercicio de otros derechos humanos, como el derecho a la educación o el derecho a la identidad cultural" ${ }^{39}$

Después del caso de la Comunidad Yakye Axa vs. Paraguay (Fondo 2005) la Corte IDH mantuvo su doctrina en términos prácticamente idénticos ${ }^{40}$.

En relación con el amplio significado y la interconexión entre la tierra y la cultura de los pueblos indígenas, sus comunidades e integrantes, dijo la Corte IDH ya en 2006, en el caso de la Comunidad Indígena Sawhoyamaxa vs. Paraguay que para los pueblos indígenas la tierra tiene una "significación especial", por lo que "toda denegación al goce o ejercicio de los derechos territoriales" acarrea el menoscabo de valores relevantes y el peligro consecuente "de perder o sufrir daños irreparables en su vida e identidad y en el patrimonio cultural por transmitirse a las futuras generaciones" $"$.

Así, bajo este enfoque se asegura un derecho humano a la identidad cultural centrado en el reconoci-

33 CORTE IDH. Caso Comunidad Indígena Yakye Axa vs. Paraguay, 17 junio 2005. párr. 124.

34 CORTE IDH. Caso Comunidad Indígena Yakye Axa vs. Paraguay, fondo, reparaciones y costas, 17 de junio de 2005, párr. 147.

35 CORTE IDH. Caso Comunidad Indígena Yakye Axa Vs. Paraguay, fondo, reparaciones y costas, 17 de junio de 2005, párr. 51.

36 CORTE IDH. Caso Comunidad Indigena Yakye Axa Vs. Paraguay, fondo, reparaciones y costas, 17 de junio de 2005, párr. 51.

37 CORTE IDH. Caso Comunidad Indígena Yakye Axa Vs. Paraguay, fondo, reparaciones y costas, 17 de junio de 2005, párr. 135.

38 CORTE IDH. Caso comunidad indigena Yakye Axa vs. Paraguay, fondo, reparaciones y costas, 17 de junio de 2005, párr. 158 k.

39 CORTE IDH. Caso comunidad indígena Yakye Axa vs. Paraguay, fondo, reparaciones y costas, 17 de junio de 2005, párr. 167.

40 CORTE IDH. Caso comunidad indigena Yakye Axa vs. Paraguay, fondo, reparaciones y costas, 17 de junio de 2005, párr. 135; Caso comunidad indigena Sawhoyamaxa vs. Paraguay, fondo, reparaciones y costas, 17 de junio de 2005. párr. 118; Caso de la Comunidad Indigena Xákmok Kásek vs. Paraguay, sentencia de 24 agosto 2010, ondo, reparaciones y costas. párr. 174. Caso del Pueblo de Saramaka vs. Surinam (2007), sentencia de 28 de noviembre de 2007, excepciones preliminares, fondo, reparaciones y costas. párr. 120; Caso Pueblos Kalina y Lokono vs. Surinam, fondo reparaciones y costas (2015) párr.. 130, Caso comunidad indígena Xákmok Kásek Vs. Paraguay, sentencia de 24 agosto 2010, fondo, reparaciones y costas. parrs. 171,172, 174, 175, 176, 177, 179, 182 de item VI: Derecho a la propiedad comunitaria, garantías judiciales y protección judicial (artículos 21.1, 8.1 y 25.1 CADH), pág. 44-46.

${ }^{41}$ CORTE IDH. Caso comunidad indigena Sawhoyamaxa vs. Paraguay, fondo, reparaciones y costas, 17 de junio de 2005. párr. 222. 
miento y la protección de las manifestaciones culturales como "formas de vida", cultura, lengua, etc. de los pueblos y sus culturas, cuya vulneración supone un riesgo a su sobrevivencia colectiva. Por tanto, señaló que el derecho a la identidad cultural debe ser resguardado por medio de medidas efectivas que el Estado deberá garantizar a los miembros de la Comunidad para que puedan continuar viviendo su modo de vida tradicional, conforme a su identidad cultural, estructura social, sistema económico, costumbres, creencias y tradiciones distintivas" ${ }^{\prime 2}$.

\subsection{Fundamentación como derecho social y cultural (DESC) a la luz del 26 de la CADH:}

En el caso de las Comunidades indígenas miembros de la Asociación Lhaka Honbat (nuestra tierra) vs. Argentina (2020) ${ }^{43}$, las Comunidades de los pueblos indígenas Wichi (Mataco), Iyjwaja (Chorote), Komlek (Toba), Niwackle (Chulupi) y Tapy'y (Tapiete) de la "Asociación Lbaka Honhat" que habitan al sur del río Pilcomayo, en el Chaco semi árido de la Provincia de Salta, Argentina, denunicaron la construcción del Puente Internacional sobre el Río Pilcomayo y un conjunto de otras vías y edificaciones instalados en su territorio. Asimismo, que en los últimos 60 años sufrieron la interferencia en sus tierras y en su forma de vida por las acciones de agricultores "criollos" y sus animales, con quienes disputan los espacios necesarios para su sobrevivencia.

Señaló la Corte que el "derecho a participar en la vida cultural... incluye el derecho a la identidad cultural" a la luz de la Carta de la OEA que establece (artículos 30, 45 f., 47 y 48) que contiene el compromiso de los Estados para que sus pueblos alcancen un desarrollo integral que abarca el campo, la cultura, y la incorporación y creciente participación de los sectores marginales de la población y en la vida cultural a fin de lograr la plena integración de la comunidad nacional; para estimular la cultura y preservar y enriquecer el patrimonio cultural de los pueblos americanos" 4 . Asimismo, dijo que su decisión considera "el derecho a 'participar en la vida cultural' en un aspecto específico, que es el derecho a la 'identidad cultural"', en especial relación con la "la afectación a los rasgos culturales propios o identitarios, a la cultura como 'modo de vida". Agregó que la noción de "identidad cultural” está contenida en el Convenio 169 de la OIT, en la DADPI y que puede entenderse incorporada en la DNUDPI y que sido utilizada por la Corte en favor de comunidades indígenas. Luego que "la 'identidad cultural' es un 'derecho humano fundamental y de naturaleza colectiva de las comunidades indígenas, que debe ser respetado en una sociedad multicultural, pluralista y democrática”" ${ }^{45}$

En relación a la articulación de las fuentes internacionales que configuran el derecho humano a la identidad cultural, afirmó la Corte que:

“... las normas indicadas deben entenderse y aplicarse de forma armónica con otros compromisos internacionales de los Estados, tales como los que surgen, por ejemplo, del artículo 15 del [PIDESC] y del artículo 27 del [PDCP] o del Convenio 169. Por ello, no corresponde entender que tales normas mandan políticas estatales que propendan a la asimilación de grupos minoritarios, o con pautas culturales propias, a una cultura que se pretenda mayoritaria o dominante. Por el contrario, los mandatos de procurar un desarrollo 'integral', 'incorporar' y acrecentar la 'participación' de sectores poblacionales para su 'plena integración', estimular la cultura y 'preservar y enriquecer' el patrimonio cultural, deben entenderse en el marco del respeto a la propia vida cultural de los diversos grupos, tales como comunidades indígenas. Por lo tanto, la 'participación', ‘integración' o ‘incorporación' en la 'vida cultural' deben procurarse sin perjuicio de la diversidad cultural, y entenderse de modo respetuoso de la misma y de los derechos de los distintos grupos y las personas que los integran" ${ }^{46}$.

\footnotetext{
42 CORTE IDH. Caso del Pueblo Xucuro vs. Brasil, sentencia de 5 febrero de 2018. párr. 188.

43 CORTE IDH. Caso comunidades indígenas miembros de la Asociación Lhaka Honhat (nuestra tierra) vs. Argentina, fondo, reparaciones y costas, sentencia de 6 de febrero de 2020.

44 CORTE IDH. Caso comunidades indígenas miembros de la Asociación Lhaka Honhat (nuestra tierra) vs. Argentina, fondo, reparaciones y costas., párr. 231., sentencia de 6 de febrero de 2020.

45 CORTE IDH. Caso comunidades indigenas miembros de la asociación Lhaka Honhat (nuestra tierra) vs. Argentina, fondo, reparaciones y costas., párr. 231 (Nota 233), sentencia de 6 de febrero de 2020.

46 CORTE IDH. Caso comunidades indígenas miembros de la asociación Lhaka Honhat (nuestra tierra) vs. Argentina, fondo, reparaciones y costas. párr. 231 (Nota 234). sentencia de 6 de febrero de 2020.
} 
En cuanto al contenido del derecho humano a la identidad cultural dijo la Corte que:

“... el derecho de las personas a disfrutar de su propia cultura [puede] guardar relación con modos de vida estrechamente asociados al territorio y al uso de sus recursos... como es el caso de los miembros de comunidades indígenas. El derecho a la identidad cultural, puede manifestarse, entonces, de diversas formas; en el caso de los pueblos indígenas se observa, sin perjuicio de otros aspectos, en 'un modo particular de vida relacionado con el uso de recursos terrestres [...].el derecho a la propiedad colectiva de los pueblos indígenas está vinculado con la protección y acceso a los recursos naturales que se encuentran en sus territorios... el bienestar físico, espiritual y cultural de las comunidades indígenas está íntimamente ligado con la calidad del medio ambiente en que desarrollan sus vidas" ${ }^{\prime 4}$.

“...'el vínculo de los miembros de una comunidad con sus territorios' resulta 'fundamental e inescindible para su supervivencia alimentaria y cultural'”48.

No obstante afirmación precedente que destaca el valor de la "supervivencia alimentaria y cultural", la sentencia del caso Lhaka Honhat vs. Argentina (2020) fundamenta el derecho humano a la identidad cultural como un derecho social y cultural, en tanto afirma que el derecho a la identidad cultural está contenido en el derecho a la participación en la vida cultural ${ }^{49}$. De esta forma, ocurre un "desplazamiento" de la hermenéutica precedente centrada en la protección de tierras y recursos naturales (21 CADH), la igualdad y no discriminación (24 CADH), en relación a las obligaciones de respeto de los derechos y de adecuación normativa $(1.1$ y $2 \mathrm{CADH})$, que sostienen su vinculación con el derecho a la vida en sentido colectivo. En particular, la Corte IDH recurrió al artículo 26 de la CADH (en relación a los artículos 1.1. y 2 de la CADH), que establece la obligación de desarrollo progresivo de los DESC por parte del Estado. Luego, dentro de dichos DESC, en base a un conjunto de fuentes internacionales de diversa naturaleza, invocó el "derecho a la participación en la vida cultural" como marco del derecho a la identidad cultural. También, en este caso, la Corte desarrolló el contenido material del derecho humano a la identidad cultural, afirmando su interdependencia con otros derechos como el derecho humano al agua, a la alimentación adecuada, a la vivienda adecuada, al medio ambiente y a la participación (vinculada a la consulta $\left.{ }^{50}\right)^{51}$.

Finalmente, en relación a los alcances de las obligaciones progresivas de cumplimiento, en la sentencia del caso Lhaka Honhat vs. Argentina (2020), la Corte consideró que el artículo 26 de la CADH está comprendido en el deber genérico de respetar y garantizar los derechos (artículos 1.1 y 2 de la CADH). Ergo, la obligación de garantía, en relación a la obligación de desarrollo progresivo (artículo 26) implica el deber positivo de adoptar medidas eficaces (jurídicas, políticas o administrativas) para proteger los derechos humanos y de establecer procedimientos judiciales y/o administrativos para investigar y sancionar eventuales violaciones, sea por el Estado o privados" ${ }^{2}$.

\footnotetext{
47 CORTE IDH. Caso comunidades indígenas miembros de la asociación Lhaka Honhat (nuestra tierra) vs. Argentina, fondo, reparaciones y costas, párr. 251 sentencia de 6 de febrero de 2020.

48 Caso comunidades indígenas miembros de la Asociación Lhaka Honhat (nuestra tierra) vs. Argentina, fondo, reparaciones y costas, párr. 252. sentencia de 6 de febrero de 2020.

49 CORTE IDH. Caso comunidades indígenas miembros de la asociación Lhaka Honhat (nuestra tierra) vs. Argentina (2020), párr. 231 (Nota 233). v. FAUNDES, Juan Jorge; CARMONA, Cristobal; SILVA, Pedro Pablo. La Corte IDH . Hermenéutica del derecho al medio ambiente sano, a la identidad cultural y a la consulta, a la luz de la sentencia "Lhaka Honhat (nuestra tierra) vs. Argentina" (2020). Revista Brasileira de Políticas Públicas, Brasília, v. 10, n. 2, p. 635-666, 2020. p. 655-658.

50 CORTE IDH. Caso comunidades indigenas miembros de la asociación Lhaka Honbat (nuestra tierra) vs. Argentina, fondo, reparaciones y costas, párr. 254., sentencia de 6 de febrero de 2020. CORTE IDH , Caso comunidades indígenas miembros de la asociación Lhaka Honbat (nuestra tierra) vs. Argentina (2020), párr. 209.

51 También planteó una extensa fundamentación del derecho humano al medio ambiente, en interrelación con el derecho humano a la identidad cultural pero tal estudio escapa a la capacidad de extensión de este trabajo. v. FAUNDES, Juan Jorge; CARMONA, Cristobal; SILVA, Pedro Pablo. La Corte IDH. Hermenéutica del derecho al medio ambiente sano, a la identidad cultural y a la consulta, a la luz de la sentencia "Lhaka Honhat (nuestra tierra) vs. Argentina" (2020). Revista Brasileira de Politicas Públicas, Brasilia, v. 10 , n. 2 p. $635-666,2020$. p. $655-658$.

52 CORTE IDH. Caso comunidades indígenas miembros de la asociación Lhaka Honhat (nuestra tierra) vs. Argentina (2020), párr. 287-289.
} 


\section{4 Derecho a la identidad cultural como filtro hermenéutico para la Corte IDH:}

La comprensión del derecho humano a la identidad cultural introduce una hermenéutica que se extiende a otros derechos. En este sentido, el derecho funciona, al mismo tiempo, como un contenido sustantivo que debe garantizarse y como lo que llamamos un filtro hermenéutico ${ }^{53}$. Se trata de que el derecho humano a la identidad cultural irradie hacia las diversas categorías de derechos humanos que amparan los derechos de los pueblos indígenas en el ámbito doméstico, recomprendiendo derechos, ampliando su entendimiento, dotando de contenido o delimitándolo. En consecuencia, bajo esta perspectiva interpretativa el derecho humano a la identidad cultural incluso puede alcanzar el contenido de los dispositivos constitucionales que, a la luz de la labor jurisdiccional, dialogan con los derechos asegurados en los instrumentos internacionales de derechos humanos.

En lo concreto este mandato exige la comprensión de los comportamientos a la luz de los significados y visión del mundo propio de la comunidad tradicional, desplazando la interpretación conforme la cultura dominante a la cual mayoritariamente pertenece el intérprete judicial ${ }^{54}$. Al respecto dijo la Corte IDH que:

“... al interpretar y aplicar su normativa interna, los Estados deben tomar en consideración las características propias que diferencian a los miembros de los pueblos indígenas de la población en general y que conforman su identidad cultural." ${ }^{55}$.

$\mathrm{Al}$ efecto, la Corte afirmó un deber hermenéutico general, conforme el cual el derecho fundamental a la identidad cultural es un marco de "interpretación transversal para concebir, respetar y garantizar el goce y ejercicio de los derechos humanos de los pueblos y comunidades indígenas protegidos por la Convención y por los ordenamientos jurídicos internos" ${ }^{\prime 56}$. Entonces, este deber de filtraje del derecho humano a la identidad cultural determina, entre otros elementos, que: (i) los derechos de los pueblos indígenas deben ser comprendidos a la luz de la cosmovisión indígena y de los elementos inmateriales de sus vivencias; (ii) se deben asegurar las tierras y territorios indígenas en que viven como imprescindibles para su existencia y para la preservación de su cultura - material e inmaterialmente-; (iii) se trata de un deber de diligencia que recae en el Estado que le impone garantizar que los pueblos indígenas, otros grupos tradicionales y sus integrantes vivan de acuerdo con su identidad cultural, como presupuesto de su propia sobrevivencia.

\footnotetext{
53 Recogemos los conceptos de "Filtraje Constitucional" y "Filtragem Constitucional" y la idea de la eficacia irradiante de los derechos fundamentales. v. Barroso, Luis Roberto. Curso de Direito Constitucional Contempoâneo. Os conceitos fundamentais e a contruçã de novo modelo. Sao Paulo: saraiva jur, 2019. p. 517. SCHIER, Paulo Ricardo. Filtragem Constitucional. Porto alegre: Sergio Antonio Fabris, 1999. SARMENTO, Daniel. Direitos Fundamentais e Relações Privadas. 2. ed. Rio de Janeiro: Editora Lumen Juris, 2010. p. 64-75.

${ }^{54}$ FAUNDES, Juan Jorge. El derecho fundamental a la identidad cultural de los pueblos indígenas: un derecho matriz y filtro hermenéutico para las constituciones de América Latina: la justificación. Revista Brasileira de Políticas Públicas, Brasília, v. 10, n. 2, p. 635-666, 2020. MELLO, Patricia Perrone Campos; ACCIOLY, Clara Lacerda. El derecho fundamental a la identidad cultural y el constitucionalismo en red en la jurisprudencia del Supremo Tribunal Federal de Brasil. En: FAUNDES, Juan Jorge; RAMÍREZ, Silvina (ed.). Derecho fundamental a la identidad cultural, abordajes plurales desde América Latina. Santiago: RIL, Universidad Autónoma de Chile, 2020. MELLO, Patricia Perrone Campos; FAUNDES, Juan Jorge. Constitucionalismo em rede: o direito à identidade cultural dos povos indígenas como filtro hermenêutico para tutela da tradicionalidade da ocupação da terra. En: Rossito, Flávia Donini et. al. Quilombolas e outros povos tradicionais. Curitiba: CEPEDIS, 2020. p. 317-339.

55 Corte IDH. Caso Comunidad Indígena Yakye Axa vs. Paraguay, fondo, reparaciones y costas, sentencia de 17 de junio 2005 , párr. 51.

56 CORTE IDH. Caso del Pueblo Indigena Kichwa de Sarayaku vs. Ecuador, sentencia de 12 junio 2012. párr. 213.
} 


\section{Estudio de casos}

\subsection{Sentencia Corte Suprema Justicia Nacional Argentina: Acción declarativa de inconstitucionalidad Asociación Lhaka Honhat contra Salta Provincia y otros solicitud y acción declarativa de certeza, $2005^{57}$.}

Como ya sintetizamos al introducir la sentencia de la Corte IDH recaída en el caso, las Comunidades de de la "Asociación Lhaka Honhat" que habitan al sur del río Pilcomayo, en el Chaco semi árido de la Provincia de Salta, Argentina, denunciaron la construcción de una mega obra vial y la interferencia en sus tierras y en su forma de vida por las acciones de agricultores "criollos" y sus animales con quienes disputan los espacios necesarios para su sobrevivencia.

Atendiendo a la Constitución Nacional de Argentina y a la recepción de los derechos indígenas contenidos en ella estos se condensan de forma austera $a^{58}$ en un único precepto, el articulo 75 inciso $\mathrm{N}^{0} 17^{59}$ que fue introducido en el año 1994. Las actuaciones de la Asociación Lhaka Honhat se vienen sucediendo desde años anteriores en los que se iniciaban sus primeras estrategias de defensa jurídica. Posteriormente se presentaron las primeras acciones judiciales por la responsabilidad del Estado Argentino, llevando sus reivindicaciones hasta la CIDH, posteriormente a la Corte IDH en el año 2012.

La Asociación Lhaka Honhat accionó por la afectación de sus derechos mediante diversos recursos de amparo y acciones declarativas de inconstitucionalidad conocidas por la Corte Suprema de Justicia de la Nación de Argentina (CSJN) Primero en el año 1995 solicitó el amparo constitucional para la suspensión de las obras relativas al puente internacional, recurso que fue desestimado por la CSJN ${ }^{60}$. Posteriormente, en el año 2000 las comunidades representadas por la Asociación interpusieron un nuevo recurso de amparo ante la CSJN, pero la CSJN desestimó la acción nuevamente. Más tarde, en 2005 la Asociación Lhaka Honhat presentó una acción declarativa de inconstitucionalidad ${ }^{61}$, también desestimada por la CSJN. Revisaremos los argumentos de esta última decisión de la Corte Suprema Argentina.

La ley provincial 7352 de 2005 convocaba a una consulta popular vinculante a los pobladores de del departamento, consultando sobre su voluntad de entregar las tierras correspondientes a aquellos lotes a sus actuales ocupantes, aborígenes y criollos. Así se sometía el derecho de propiedad comunitaria de los pueblos indígenas que habitan desde tiempos inmemoriales esas tierras, a la voluntad de sus actuales ocupantes. Precisamente, aquellos criollos y pobladores de la zona (no indígenas) contra quienes las comunidades reclaman. La comunidad manifestó que esta ley trasgredía directamente la Constitución Nacional (arts. 14,16, 17, 31 y 75 inc. 17), la Declaración de los Derechos del Hombre y del Ciudadano (arts. $2^{\circ}$ y $17^{\circ}$ ), la Decla-

57 CSNJ. A. 1596, XLI. Acción declarativa de inconstitucionalidad, Asociación Lhaka Honhat contra Provincia de Salta y otros. Acción declarativa de certeza, sentencia de 27 de septiembre de 2005.

58 ZIMERMAN, Silvina. Estándares internacionales de derechos bumanos sobre el derecho indígena a la tierra y al territorio: un estudio sobre su contenido normativo y sobre el desarrollo de pautas para la creación de garantías de protección. 2014. Tesis (Doctoral). Universidad de Buenos Aires, Buenos Aires, 2014. p. 161.

59 Art. $75 \mathrm{~N}^{\circ} 17$ :

"Corresponde al Congreso: Reconocer la preexistencia étnica y cultural de los pueblos indígenas argentinos. Garantizar el respeto a su identidady el derecho a una educación bilingüe e intercultural; reconocer la personería Jurídica de sus comunidades, y la posesión y propiedad comunitarias de las tierras que tradicionalmente ocupan...

Asegurar su participación en la gestión referida a sus recursos naturales y a los demás intereses que los afecten. Las provincias pueden ejercer concurrentemente estas atribuciones".

60 Recursos de Amparo presentados por la Asociación Lhaka Honhat contra el Poder Ejecutivo de la Provincia de Salta (i) para la suspensión inmediata de las obras relativas al puente internacional en el año 1995 (Resolución de 10/12/1997); (ii) contra el Decreto 461/99 y la Resolución 423/99 en el año 2000.

${ }^{61}$ CSJN, A. 1596. XLI. Asociación de Comunidades Aborígenes Lhaka Honhat c/ Salta, Provincia de y otro s/ acción declarativa de certeza., 27 de septiembre de 2005. La Asociación actuó por derecho propio y de los miembros que la componen, requiriendo la declaración de inconstitucionalidad de la ley provincial 7352, promulgada por el decreto 1492/05. 
ración Universal de los Derechos Humanos (arts. 17 y 25), la Declaración Americana de los Derechos del Hombre (arts. XI y XXIII), el PIDESC (arts. 11 y 12 ), la CADH (arts. 1 y 21) y el Convenio 169 de la OIT (arts. 3, 4,5, 6, 8, 13, 14, 17, 30 y 35). Alegó que la ley dictada contrariaba actos propios de reconocimiento de posesión de las tierras cuestionadas ${ }^{62}$ y vulneraba de los compromisos asumidos por la Provincia y el Estado Nacional ante la CIDH en el marco de un "proceso de solución amistosa" que se venía realizando con estas comunidades indígenas desde el año $2000^{63}$. A su vez, los peticionarios reclamaron la responsabilidad internacional del Estado Nacional habida cuenta de la violación de tratados internacionales, por los efectos que la ley local indicada les generaba y por omisión del Estado al no haber adoptado las medidas oportunas para garantizar los derechos de las comunidades indígenas y tratar de evitar su violación inminente, de conformidad con lo dispuesto en el art. 75, N¹7, de la Constitución Nacional.

La CSJN señaló que:

“.. que no se advierte cuáles han sido las omisiones que se imputan al Estado Nacional en orden a la previsión constitucional contenida en el art.75 inc. 17 de la Constitución Nacional [...] tampoco se observa con claridad la responsabilidad internacional que podría acarrear al Estado el dictado de la ley provincial en el marco del "proceso de solución amistosa ante la [CIDH]"'.

Para justificar la desestimación de la acción, el alto Tribunal, en particular, considera entre sus argumentos que la cuestión no es de índole federal y que por tanto el Estado Nacional quedaría apartado como parte sustancial del proceso, ya que entiende que ésta es de índole local y competencia de poderes provinciales. Instruyendo a los peticionarios el agotar las vías ordinarias de orden provincial y acudir al tribunal mediante vía de recurso extraordinario del (art. 14 de la Ley No48). Explica - desde su perspectiva- que tanto el art. 75 inc. 17 de la Constitución Nacional tiene su correlato en el art. 15 de la Provincia de Salta en que esta Provincia federal reconoce un extenso estatuto de derechos a los pueblos indígenas.

Para la CSJN el conflicto normativo reclamado pertenece al ámbito local y, por tanto, requiere para su solución la interpretación y aplicación del ordenamiento jurídico provincial, sin perjuicio de la eventual cuestión federal en los términos del art. $75 . N^{\circ} 17$ de la Constitución Nacional que podría habilitar la instancia extraordinaria ante la Corte Suprema.

Más allá de la cuestión de las jurisdicciones domésticas formulada, con el argumento formal de la incompetencia, el alto Tribunal argentino deniega el amparo a los derechos de las comunidades indígenas que están fundados en el conjunto de instrumentos internacionales de protección de derechos humanos de los pueblos indígenas ratificados por Argentina y en la propia Constitución Federal, los que fueron vulnerados por las autoridades provinciales, incluso contra el texto expreso de la Constitución provincial.

Así, es relevante considerar en el caso que la decisión CSJN, no solo rechaza la acción conforme la cuestión de competencia federal y local que indica, generando los efectos internos propios de dicha decisión. La CSJN, al mismo tiempo, se desentiende de las normas que conforman un corpus iuris de derechos humanos a la luz de CADH (en relación a un conjunto de otros instrumentos de derecho internacional de los derechos humanos, universales y regionales, invocado por los accionantes de amparo), aplicables al caso concreto. En consecuencia, el Estado Argentino en su conjunto incurre en responsabilidad internacional por la violación de sus propios compromisos en materia de Derecho Internacional ${ }^{64}$.

Por otra parte, una comprensión del caso, armónica con los derechos de las comunidades Lakha Honhat, en especial a la luz de la CADH y bajo la concepción de un Derecho Común Interamericano de los derechos humanos, inclusivo de los derechos de los pueblos indígenas, se expresa en el voto razonado del Magistrado

\footnotetext{
62 Decretos Provinciales No2609/91, 18/93 y 3097/95.

63 Obligación emanada de la Ley No 24.071 de compromisos asumidos formalmente por la provincia y el Estado de Argentina con la CADH (año 2000).

${ }^{64}$ Argentina ratificó la CADH (14.8.1984), aprobada mediante la ley 23054 (Boletín Oficial, 27.3.1984). En 1994 se introdujo la reforma constitucional, al artículo $75 \mathrm{~N}^{\circ} 22$ que estableció también que ciertos tratados sobre derechos humanos —entre ellos la $\mathrm{CADH}$ - "en las condiciones de su vigencia, tienen jerarquía constitucional”.
} 
Carlos S. Fayt quien expresó que:

“.. se persigue la declaración de inconstitucionalidad de la convocatoria al electorado a expresar su voluntad en comicios, de cuyo resultado eventualmente podría surgir una vulneración de los derechos constitucionales de un sector de por sí vulnerable" 65 .

"[...] que es deber de los Estados 'tomar en consideración las características propias que diferencian a los miembros de los pueblos indígenas de la población en general y que conforman su identidad cultural...', criterio rector para 'valorar el alcance y contenido de los arts. de la Convención Americana (caso Comunidad Indígena Yakye Axa vs. Paraguay, sentencia del 17 de junio de 2005)”.

Por último, este voto disidente indica que el Gobierno de la Provincia de Salta debe "abstenerse de realizar la consulta popular prevista en la ley impugnada, así como de todo acto que conduzca a su realización” y en el marco del art. 75 inc. 17 y 22 de la Constitución Nacional, se ordene al Estado Nacional que "adopte las medidas necesarias a los fines de evitar que la consulta popular se realice" ${ }^{" 66}$.

La decisión de mayoría de la CSJN no acoge el enfoque del Ius Constitucionale Commune, en relación a un corpus iuris latino americano, desconociendo en lo concreto la interrelación existente entre el derecho de propiedad comunitaria, la forma de vida de los pueblos indígenas y el derecho humano a la identidad cultural de los pueblos indígenas, del modo que ese derecho se ha venido reconocido por la Corte IDH en su jurisprudencia y el deber correlativo del Estado.

\subsection{Corte Suprema de Chile, sentencia que ordena cumplir en el ámbito nacional la decisión de la Corte IDH del caso "Segundo Aniceto Norín Catrimán y otros (Lonkos, dirigentes y activistas del pueblo indígena Mapuche) respecto de la República de Chile (2014) ${ }^{67}$}

Esta sentencia ordena cumplir la sentencia de la Corte $\mathrm{IDH}^{68}$ que conoció el caso de un grupo de líderes y autoridades del Pueblo Mapuche (Chile) que alegaron la violación de los derechos asegurados en los artículos 8.1, 8.2, 8.2.f, 8.2.h, 9, 13, 23 y 24 de la CADH, en relación con las obligaciones establecidas en los artículos 1.1 y 2 de la misma Convención debido a su procesamiento y condena por presuntos delitos terroristas $^{69}$. Los demandantes sostuvieron (junto a la denuncia de por una tramitación irregular que afectó gravemente el debido proceso) que que la aplicación de la Ley chilena que sanciona conductas terroristas (Ley No18.314) se basó en su identidad racial y no en las conductas por las que fueron acusados y condenados. En consecuencia, que había existido un acto de discriminación en su contra basado en criterio de $\mathrm{raza}^{70}$. Al respecto, resolvió la Corte IDH que en este caso los tribunales nacionales no consideraron que las víctimas tenían la condición de miembros de un pueblo indígena “y, en particular, la posición de autoridades tradicionales que ocupaban...”. Asimismo, que:

"Los Estados, para garantizar efectivamente los derechos consagrados en el artículo 7 de la [CSDH], en relación con el artículo 1.1 de la misma, al interpretar y aplicar su normativa interna deben tomar en consideración las características propias que diferencian a los miembros de los pueblos indígenas de la

\footnotetext{
65 Voto disidente del Ministro Dr. D. CARLOS S. FAYT. A. 1596, XLI. Acción declarativa de inconstitucionalidad Asociación Lhaka Honhat contra Salta Provincia y otros solicitud y acción declarativa de certeza. CSNJ, 2005, párr. $2^{\circ}$.

${ }_{66}$ Voto disidente del Ministro DR. D. E. RAUL ZAFFARONI (A.1596. XLI Acción declarativa de inconstitucionalidad Asociación Lhaka Honhat contra Salta Provincia y otros solicitud y acción declarativa de certeza. CSNJ, 2005, párr. 2.

67 Corte Suprema de Chile, Rol AD-1386-2014, sentencia, Pleno, 16 de mayo de 2019.

68 CORTE IDH. Caso Norín Catrimán y otros (dirigentes, miembros y activista del Pueblo Indígena Mapuche) Vs. Chile, 29 mayo 2014 (Fondo, reparaciones y costas).

69 El Estado de Chile, realizó la declaración de reconocimiento de pleno derecho de la competencia de la Corte IDH, el 21 de agosto de 1990, conjuntamente con la ratificación de la CADH.

70 Se trató de un conjunto de causas penales, de juicios diferentes que llevaron a cuatro peticiones iniciales ante la CIDH y que ella denunció como un solo caso a la Corte. En uno de los casos denunciados, el longko Pascual Pichun de Temulemu, el longko Aniceto Norin de Didaico y Patricia Troncoso (integrante no indígena del movimiento) fueron condenados en 2003 a 5 años y un día de presidio por los delitos de "amenaza terrorista".
} 
población en general y que conforman su identidad cultural"’11.

En cuanto al fondo del caso, dispuso la Corte Interamericana que las sentencias condenatorias chilenas impugnadas de $2004^{72}$ se fundaron en una ley de dudoso origen violando principios como el de legalidad y derecho a la presunción de inocencia, arrojando la imposición de penas accesorias que contravinieron en restricciones indebidas y desproporcionadas al derecho de pensamiento y expresión y al ejercicio de derechos políticos, sobre la base de estereotipos y prejuicios, violando el principio de igualdad y no discriminación, configurando "violaciones al derecho de la defensa protegido en el artículo 8.2.f de la Convención"73.

En cumplimiento de la sentencia de la Corte IDH referida, la Corte Suprema de Chile ordenó dejar sin efecto las condenas de 2004. Así, para la Corte Suprema de Chile, en su sentencia de 2019:

“... la actuación en el orden interno del Estado de Chile...y las referidas decisiones condenatorias [perdieron] sus efectos... su subsistencia supone la permanencia de actuaciones que han sido declaradas por el tribunal internacional competente como conductas lesivas de las garantías fundamentales. En virtud de lo anterior esta Corte Suprema resolvió declarar que los fallos condenatorios citados han perdido los efectos que les son propios" "ᄁ4.

Luego, invocando el artículo $5^{\circ}$ inc. $2^{\circ}$ de la Constitución chilena, expresa que el ejercicio de la soberanía interna del Estado se encuentra limitada por los derechos esenciales que emanan de la naturaleza humana y que los órganos del Estado tienen el deber de respetarlos y promoverlos. Así - continúa- que el ordenamiento jurídico interno "reconoce que los derechos humanos están por sobre todo poder del Estado, constituyendo una categoría especial de derechos subjetivos que cuentan con protección nacional [constitucional] e internacional" ${ }^{15}$. En consecuencia, que bajo la competencia que el propio Estado le ha otorgado a la Corte IDH y conforme el artículo 63 de la CADH, cuando la Corte determine que ha existido violación de un derecho o libertad protegidos por la $\mathrm{CADH}$, “dispondrá que 'se garantice al lesionado en el goce de su derecho o libertad conculcados' y ‘que se reparen las consecuencias de la medida o situación que ha configurado la vulneración de esos derechos..."’76.

Así, conforme la obligación de interpretar los tratados de buena fe y teniendo en cuenta su objeto y fin (a la luz de la Convención de Viena de Derechos de los Tratados), en armonía con la obligación del artículo 29 de la CADH (interpretación evolutiva), de "dar a sus disposiciones el alcance que asegure el grado máximo de protección de los derechos que reconoce" y "mediante el control de convencionalidad, los jueces nacionales forman parte del sistema interamericano en la protección estándares de cumplimiento y garantía de tales derechos", establecidos por la Corte ${ }^{77}$. En particular, expresa que:

“... En dicha labor de paráfrasis, de obediencia y acatamiento a los estándares mínimos que el Estado suscriptor se obligó a observar, los Jueces deben utilizar el Corpus Iuris Interamericano y la jurisprudencia de la Corte, y los métodos interpretación de derechos Pro Homine, de Progresividad, y Proporcionalidad, los cuales amplían su potestad jurisdiccional." ${ }^{38}$.

De esta forma, podemos identificar en la decisión de la Corte Suprema de Chile un diálogo con la Corte IDH, sobre la base del reconocimiento de la existencia de un derecho común latinoamericano de los derechos humanos - que la Corte Interamericana ha establecido como inclusivo de los derechos de los pueblos

\footnotetext{
${ }^{71}$ CORTE IDH. Caso Norín Catrimán y otros (dirigentes, miembros y activista del Pueblo Indígena Mapuche) Vs. Chile, 29 mayo 2014 (Fondo, reparaciones y costas), párr. 37.

72 Tribunal de Juicio Oral en lo Penal de Angol de 27 de septiembre de 2003 y de 22 de agosto de 2004 y por la Corte de Apelaciones de Concepción con fecha 4 de junio de 2004.

73 CORTE IDH. Caso Norín Catrimán y otros (dirigentes, miembros y activista del Pueblo Indígena Mapuche) Vs. Chile, 29 mayo 2014 (Fondo, reparaciones y costas), párr. 421.

74 Corte Suprema de Chile, Rol AD-1386-2014, sentencia, Pleno, 16 de mayo de 2019, párr. $5^{\circ}$.

75 Corte Suprema de Chile, Rol AD-1386-2014, sentencia, Pleno, 16 de mayo de 2019, párr. 6

76 Corte Suprema de Chile, Rol AD-1386-2014, sentencia, Pleno, 16 de mayo de 2019, párr. 7.

77 Corte Suprema de Chile, Rol AD-1386-2014, sentencia, Pleno, 16 de mayo de 2019, párrs. 8-9.

78 Corte Suprema de Chile, Rol AD-1386-2014, sentencia, Pleno, 16 de mayo de 2019, párr. 19.
} 
indígenas, según vimos-, lo cual, a su vez se enmarca en el enfoque del ICCAL que venimos siguiendo.

En particular, al Corte Suprema plantea cómo, por una parte, los derechos asegurados en la CADH juegan papel primordial en el control del arbitrio estatal, en un diálogo que describe expresando que estos derechos se yerguen como una potente restricción al ejercicio totalitario del poder estatal" y que, asimismo, el Estado de Derecho Democrático constituye un régimen de libertades personales, y su respectiva, protección, "que son consustanciales con los resguardos de los Derechos Humanos que se contienen en la Convención Americana" "79. Así, releva, tanto el rol de las sentencias interamericanas en la construcción de los mayores estándares de protección de los derechos asegurados en la $\mathrm{CADH}$, como las decisiones del juez nacional, "la misión práctica de supervigilar el cumplimiento de las

Normas de la Convención Americana de Derechos Humanos". Y, en particular, que identifica dos funciones específicas en el juez nacional: una, "de orden represivo" que "impone a los magistrados del foro la exigencia de no aplicar las normas internas que sean contrarias" a la CADH; la otra, "de naturaleza constructiva" que "requiere que se interprete el derecho local en concordancia con la Convención y en armonía con la jurisprudencia de la Corte Interamericana de Derechos Humanos" $\$ 0$.

Finalmente, si enlazamos las consideraciones precedentes que surgen de la sentencia de la Corte Suprema revisada que da cumplimiento a la respectiva decisión de la Corte IDH (ella, a su vez, que ordena dejar sin efecto las sentencias condenatorias de fuero local), con nuestro objeto de estudio, el derecho humano a la identidad cultural, podríamos afirmar que:

- En este caso es la sentencia de la Corte IDH la que reconoce el derecho humano a la identidad cultural, establece sus estándares y declara la violación respecto de las víctimas demandantes ante la referida Corte Interamericana.

- La sentencia nacional de la Corte Suprema chilena establece un continuo bermenéutico desde la CADH en conformidad a los estándares evolutivos desarrollados por la Corte Interamericana-y la obligación de derecho interno.

- La sentencia nacional, además, recepciona la CADH entendiéndola como articuladora de un derecho común de los derechos humanos (corpus iuris).

- $\quad \mathrm{La}$ CADH (en general y por cierto respecto del derecho humano a la identidad cultural) que impone a los jueces nacionales, como la Corte Suprema, un doble imperativo: (i) obligación de cumplimiento, respeto y garantía; (ii) obligación hermenéutica de cumplimiento conforme el sentido de la CADH alcanzado a la luz de la jurisprudencia de la Corte IDH.

La comprensión de la obligación internacional interamericana que la Corte Suprema de Chile expone en el caso, configura una forma de diálogo hermenéutico, armónica con la perspectiva del ICCAL, que impone el respeto y protección del derecho humano a la identidad cultural de los pueblos indígenas en el ordenamiento jurídico chileno, a la luz de las hermenéuticas de este derecho que hemos establecido en este trabajo.

\subsection{Sentencia Supremo Tribunal Federal de Brasil "ADPF 709":}

La ADPF $709^{81}$ es una acción de control de constitucionalidad presentada directamente al Supremo Tribunal Federal de Brasil (STF) por la Articulação dos Povos Indígenas do Brasil juntamente con diversos partidos políticos brasileños, en que se invoca violación al derecho de los pueblos indígenas a la vida y a la salud

\footnotetext{
79 Corte Suprema de Chile, Rol AD-1386-2014, sentencia, Pleno, 16 de mayo de 2019, párr. 20.

80 Corte Suprema de Chile, Rol AD-1386-2014, sentencia, Pleno, 16 de mayo de 2019, párr. 21.

81 BRASIL. Supremo Tribunal Federal. Arguição de Descumprimento de Preceito Fundamental n. 709. Relator: Ministro Luís Roberto Barroso, j. 05 de agosto de 2020.
} 
frente a la pandemia por COVID-19. Los postulantes afirman que tales pueblos presentan condiciones de vulnerabilidad epidemiológica más grave que la mayoría de los brasileños al COVID, en razón de su menor exposición a enfermedades infectocontagiosas, su modo de vida comunitario y su residencia en locales con difícil acceso a servicios de salud. Afirman, además, que el gobierno no estaría adoptando medidas adecuadas a su protección y requieren:

(i) En relación a los Pueblos Indígenas Aislados y a Pueblos Indígenas de Reciente Contacto (PIIRCs) ${ }^{82}$, la instalación de barreras sanitarias que impidan el acceso de terceros a sus áreas y la instalación de una Sala de Situación, compuesta por representantes indígenas, técnicos de salud y representantes del gobierno, para hacer el seguimiento de la pandemia, actualizar, proponer y adoptar las medidas sanitarias que se muestren necesarias, de acuerdo con su avance ${ }^{83}$.

(ii) Respecto a los Pueblos Indígenas que viven en tierras indígenas pendientes de homologación $^{84}$ y a los pueblos indígenas urbanos, atención especializada de salud por el servicio especial de salud indígena. Afirman que el gobierno federal solo presta tales servicios a los pueblos que viven en tierras demarcadas, bajo el argumento de que, no estando sus tierras homologadas no estaría plenamente demostrada su condición indígena y, por lo tanto, el derecho de acceso al servicio especializado. Sobre indígenas urbanos, clarifican que muchos no hablan la lengua y tienen necesidades y dificultades especiales que les impide acceder al Servicio Único de Salud (SUS), que presta servicios públicos de salud a los brasileños en general ${ }^{85}$.

(iii) En cuanto a todos los Pueblos Indígenas, en general, postulan la elaboración de un Plan General de Enfrentamiento a la COVID para Pueblos Indígenas, que contemple los múltiples ejes necesarios a tal fin, como: (iii.a) acceso al agua potable y alimentación, (iii.b) asistencia de salud, testeo de contagio, aislamiento y tratamiento y (iii.c) acceso a beneficios asistenciales ${ }^{86}$.

(iv) En relación a los pueblos Indígenas cuyas tierras son objeto de invasión por la minería y otras actividades ilegales, la retirada de los invasores, que ofrecen riesgo de contagio ${ }^{87}$.

El STF concedió en parte las medidas cautelares pertinentes a estos requerimientos. Sobre los Pueblos Indígenas Aislados y Pueblos Indígenas de Reciente Contacto (PIIRCs) (i), clarificó que el respeto a su aislamiento voluntario y, por lo tanto, a su identidad cultural, tiene como base su derecho a la autodeterminación, a sus instituciones, costumbres y al control sobre su propio desarrollo, conforme los artículos 2, 5 y 7 del Convenio $N^{\circ} 169$ de la OIT ${ }^{88}$. Expuso, además, basado en las Directrices del Alto Comisariado de la Organización de las Naciones Unidas para enfrentamiento de la pandemia (OACNUDH) y en la Resolución de la CIDH sobre Pandemia y Derechos Humanos en las Américas, que la protección del aislamiento y, por tanto, de la identidad cultural, en el caso de esos pueblos indígenas es la mejor forma de protección de su derecho a la vida y a la salud ${ }^{89}$ porque el no contacto evita el contagio.

\footnotetext{
82 También denominados como pueblos indígenas en "contacto inicial".

83 BRASIL. Supremo Tribunal Federal. Arguição de Descumprimento de Preceito Fundamental n. 709. Relator: Ministro Luís Roberto Barroso, j. 05 de agosto de 2020, parr. 14-31.

${ }^{84}$ El proceso de regularización de tierras indígenas depende de una etapa de identificación de los marcos y límites precisos de la tierra, con base en estudios topográficos, seguida de la declaración formal de tales límites por portaría del Ministro de la Justicia, de su homologación por decreto el Presidente de la República y del registro de la tierra en el Registro de Propiedad competente, como bien de la Unión y como tierra indígena. Tierras no homologadas son aquellas en que viven comunidades indígenas, pero cuyos límites aún no fueron reconocidos por acto oficial del Presidente de la República. BRASIL. Lei 6.001, de 19 de dezembro de 1973 ; Decreto n. 1775, de 9 de janeiro de 1996.

85 BRASIL. Supremo Tribunal Federal. Arguição de Descumprimento de Preceito Fundamental n. 709. Relator: Ministro Luís Roberto Barroso, j. 05 de agosto de 2020, parr. 36-47.

86 BRASIL. Supremo Tribunal Federal. Arguição de Descumprimento de Preceito Fundamental n. 709. Relator: Ministro Luís Roberto Barroso, j. 05 de agosto de 2020, parr. 36-47.

87 BRASIL. Supremo Tribunal Federal. Arguição de Descumprimento de Preceito Fundamental n. 709. Relator: Ministro Luís Roberto Barroso, j. 05 de agosto de 2020, parr. 33-25.0

88 BRASIL. Supremo Tribunal Federal. Arguição de Descumprimento de Preceito Fundamental n. 709. Relator: Ministro Luís Roberto Barroso, j. 05 de agosto de 2020, parr. 14-15.

89 En este sentido afirmo el STF que:
} 
En lo que se refiere a los Pueblos Indígenas que viven en tierras indígenas pendientes de homologación y a los pueblos indígenas urbanos (ii), el STF observó que la condición de indígena no se vincula al reconocimiento del derecho a la tierra por parte del Estado. El elemento esencial del reconocimiento como pueblo indígena radica en la consciencia de su propia identidad como tal, conforme establece el Convenio $\mathrm{N}^{\circ} 169$ de la OIT, artículos $1^{\circ}, 2$, y $2^{\circ}, 1$.

Con todo, previamente, el Presidente de la República ya había declarado que no demarcaría tierras indígenas en su gobierno ${ }^{90}$. En esas condiciones, se estaba negando a tales pueblos todos sus derechos posibles, ya que se negaba su derecho a la tierra, en violación a la Constitución de 1988 y se usaba ese argumento para negarles todos los demás derechos. Así eran abandonándolos a su propia suerte en medio de la pandemia y, en consecuencia, se colocaba en riesgo su sobrevivencia como pueblo. Lo mismo pasaba con indígenas urbanos, que no pierden la condición de indígenas por vivir en el contexto urbano y tienen derechos al servicio especial de salud siempre que no puedan acceder al SUS.

En el caso de esos pueblos, se identificó que estaba en riesgo el derecho a la identidad cultural, en relación a la preservación de su sobrevivencia y existencia como pueblo.

En cuanto a los Pueblos Indígenas en general (iii), el STF determinó que el Gobierno Federal debía elaborar un Plan General de Enfrentamiento al COVID para Pueblos Indígenas (Plan General), con la participación de los representantes de los indígenas. Fueron presentadas cuatro versiones de tal Plan General y resultó homologado (aprobado) condicionalmente la cuarta versión ${ }^{91}$. El Plan General garantizó múltiples servicios y prestaciones positivas en materia de salud, acceso al agua, seguridad alimentaria, habitación y beneficios asistenciales, con el fin de garantizar su protección durante la pandemia. Con el desarrollo de vacunas anti-COVID, aseguró a pueblos indígenas que habitan tierras indígenas homologadas o no, así como a indígenas urbanos sin acceso al SUS, el derecho a la vacunación prioritaria ${ }^{92}$.

En relación a la prestación de los "servicios mínimos necesarios a la subsistencia", como individuos y como pueblos, que están previstos en el Plan General, el sistema brasileño tiende a considerarlos encuadrados en la categoría de "mínimo existencial" y, por lo tanto, relacionados con la preservación de la vida y de la dignidad humana. No obstante, en la medida en que se sobrepasa tal mínimo (de difícil determinación práctica), se consideran derechos sociales de segunda generación, conectados a prestaciones positivas por parte del Estado y, en consecuencia, en este segundo plano, se sujetan más fácilmente a argumentos sobre límites presupuestarios y a la reserva de lo posible ${ }^{93}$. Bajo tales categorías, que no son perfectamente estancas o delimitables - y en cuanto al grupo más amplio de indígenas involucrados por la acción -, se puede decir que se amparó el derecho a la identidad cultural, en ambas dimensiones: tanto en la protección

\footnotetext{
"Na atual situação, em que há uma pandemia em curso, os povos em isolamento e de contato recente são os mais expostos ao risco de contágio e de extinção. Isso ocorre em razão das condiçoes de vulnerabilidade imunológica e sociocultural já narradas. Por essa razão e de acordo com diretrizes internacionais da ONU e da [CIDH], a medida protetiva mais eficaz a ser tomada em favor de tais povos é assegurar-lhes o isolamento da sociedade envolvente, por meio de barreiras ou cordões sanitários que impeçam...". BRASIL. Supremo Tribunal Federal. Arguição de Descumprimento de Preceito Fundamental n. 709. Relator: Ministro Luís Roberto Barroso, j. 05 de agosto de 2020, parr. 16-17.

90 BRASIL. Supremo Tribunal Federal. Arguição de Descumprimento de Preceito Fundamental n. 709. Relator: Ministro Luís Roberto Barroso, j. 05 de agosto de 2020 , parr. 8 .

91 BRASIL. Supremo Tribunal Federal. Arguição de Descumprimento de Preceito Fundamental n. 709. Relator: Ministro Luís Roberto Barroso, j. 16 de março de 2020,

92 BRASIL. Supremo Tribunal Federal. Arguição de Descumprimento de Preceito Fundamental n. 709. Relator: Ministro Luís Roberto Barroso, j. 16 de março de 2020, parr. 13-16.

93 El derecho al mínimo existencial es comprendido por el derecho brasileño como ligado a los derechos a la vida, dignidad y libertad y, por lo tanto, no sometido a la discreción de los poderes Legislativo y Ejecutivo, diferentemente de lo que pasa con los derechos sociales de modo general, que son realizables de acuerdo con la coyuntura económica y conforme a la "reserva de lo posible". La reserva de lo posible es comprendida por algunos autores como fáctica (inexistencia de recursos para la realización de derechos) y, por otros, como jurídica (límites democráticos para la realización de derechos, impuestos por decisión del legislador, dada la escasez de recursos y la multiplicidad de demandas). Para el debate, en el derecho brasileño, sobre contenido y límites del mínimo existencial y de la reserva de lo posible, v. SARLET, Ingo; FIGUEIREDO, Mariana Filchtiner. Reserva do possível, mínimo existencial e direito à saúde. Revista de Direitos Fundamentais \& Justiça, v. 1, n. 1, p. 171-213, out./dez. 2007; TORRES, Ricardo Lobo. O direito ao mínimo existencial. Rio de Janeiro: Renovar, 2009. p. 103-110.
} 
de su derecho a la vida; como, asimismo, en aquella relativa a derechos sociales, bajo prestaciones positivas de parte del Estado.

Finalmente, en respecto a la solicitud desocupación de invasores (iv). Primero, el STF tuvo en cuenta el público conocimiento de la existencia de millares de invasores armados en algunas de las tierras en que habitan los indígenas recurrentes. En tal contexto, temía que medidas de expulsión pudieran generar conflictos violentos y riesgos en razón de ello riesgos aún más graves para la vida de los indígenas. Además, la operación implicaría ingresar con centenas de soldados y policía en sus tierras, lo que también generaría mayor riesgo sanitario de contagio. En tal cuadro, el Tribunal concedió una cautelar alternativa (a la pretensión recurrida), determinando la elaboración y ejecución de un Plan de Aislamiento de los Invasores, de modo de impedirles tener contacto con las comunidades afectadas.

Es importante observar que, más allá de la amplitud de las cautelares concedidas, en su implementación y monitoreo se enfrentan dificultades de todos los tipos, tales como: falta de materiales, de personal, de presupuesto, fragilidad de las instituciones de protección a tales pueblos y tal vez de voluntad política ${ }^{94}$. De todas formas, el tribunal sigue buscando monitorear el cumplimiento de sus decisiones.

Así, puede destacarse de este caso que el STF en su argumentación -tanto al identificar el riesgo y al otorgar las medidas cautelares respectivas, como en su función de monitoreo del cumplimiento de estas medidas-, expresa una comprensión del derecho humano a la identidad de los pueblos indígenas que sigue la Constitución de Brasil y dialogando con la misma idea de la Corte IDH. Ahora bien, el derecho humano a la identidad cultural ha operado en diversos sentidos: como factor de riesgo en sí (respecto del derecho a la vida y sobre vivencia de los pueblos indígenas y sus miembros), como fundamento del otorgamiento prestacional de acciones de salud necesarias para la población en riesgo; como factor de adecuación de las propias acciones cautelares y las prestaciones de salud, en particular, a las condiciones sociales y culturales de los pueblos indígenas aislados o en contacto reciente cuyo resguardo ha sido requerido judicialmente.

\section{Conclusiones}

El enfoque del ICCAL apunta a la consecución de un constitucionalismo transformador y, en ese sentido, propone un diálogo entre cortes internacionales y aquellas cortes nacionales con competencia constitucional. Pero, la revisión de tal proposición, aunque fundada en mínimos comunes o universales de derechos humanos, articulados desde la $\mathrm{CADH}$, dada la diversidad de fuentes normativas y una multiplicidad de campos jurídicos que interactúan, vertical y horizontalmente, requiere un análisis caso a caso, diferenciando fuentes, efectos y titulares en concreto.

La idea de un "derecho común latinoamericano" (corpus iuris) no es estática ni cerrada. Por el contrario, se trata de una hermenéutica abierta, dinámica, en que las fuentes y sus efectos, se articulan y reorganizan, generando marcos de protección en diversas dimensiones normativas, generalmente complementarias, y múltiples efectos. Desde esta perspectiva, es posible afirmar la existencia de un derecho humano a la identidad cultural, justificado o emanado desde múltiples fuentes normativas.

Ahora bien, la Corte IDH ha dotado de contenido el derecho humano a la identidad cultural desde las diversas fuentes indicadas, particularmente la CADH (artículos 1, 2 y 63). Así, según las circunstancias respectivas, en concreto, el derecho humano a la identidad cultural comprende, a lo menos, dos dimensiones de naturaleza y alcances jurídicos distintos: (i) una como derecho a la vida (en el sentido colectivo de la sobrevivencia indígena como pueblos o grupos tradicionales), emanada de la protección de los derechos a la

94 BRASIL. Supremo Tribunal Federal. Arguição de Descumprimento de Preceito Fundamental n. 709. Relator: Ministro Luís Roberto Barroso, j. 24 de maio de 2021, parr. 13-15. 
tierra y sus recursos naturales, en relación al derecho a la igualdad y no discriminación, cuya fuente directa es la propia CADH (artículos 21 y 24); (ii) otra, como DESC (artículo $26 \mathrm{CADH}$ ), en relación al derecho a la igualdad y no discriminación (artículo $24 \mathrm{CADH}$ ), para la protección de las tierras y recursos naturales, pero también de alcance prestacional, que considera las obligaciones correlativas y progresivas de cumplimiento efectivo (caso particularmente relevante en relación a las políticas públicas de salud).

Estas dos dimensiones del derecho humano a la identidad cultural, aunque arrojan compromisos jurídicos de distinta naturaleza y alcance, no son incompatibles y, es más, pueden ser concurrentes, permitiendo elevar los estándares asociados al cumplimiento de estos derechos.

La Corte IDH reconoció el derecho a la identidad cultural respecto de los pueblos indígenas, extendiéndolo luego a otros grupos tradicionales, como los afrodescendientes; y, recientemente, lo ha entendido también como un derecho de carácter universal, en el marco del derecho a la participación en la vida cultural. Al afirmar esta titularidad universal, la Corte desplaza su fundamentación precedente y ahora estima el derecho a la identidad cultural como un derecho integrante del derecho a la participación en la vida cultural (DESC). Luego, parece alejarse de la noción de un derecho autónomo vinculado a la vida. Con todo, en sus argumentos cita latamente los fallos anteriores desarrollados desde el primer enfoque.

El derecho humano a la identidad cultural, comprendido a la luz del ICCAL, se inserta en una hermenéutica dialógica interamericana, entre la Corte IDH y múltiples ordenamientos nacionales, conformando un cuerpo jurídico común, un corpus iuris latinoamericano de derechos humanos, incluyente del derecho humano a la identidad cultural estudiado. En este contexto normativo, el derecho a la identidad cultural constituye un filtro hermenéutico en la labor jurisdiccional, contribuyendo así a la protección de los derechos humanos de los pueblos indígenas y otros grupos tribales. Ahora bien, en la perspectiva indicada, la muestra jurisprudencial revisada, evidencia que los alcances de este diálogo deben examinarse caso a caso, pudiendo presentarse, conforme la propia mirada de la judicatura nacional, en flujos más o menos intensos, conforme los países o, incluso, la oportunidad en que se presente el caso.

En el sentido precedente, examinamos un caso reciente de condena por la Corte IDH (contra Argentina) fundada, entre otros aspectos, en la decisión de la CSJN que no amparó el derecho humano a la identidad cultural, no obstante presentarse en el caso los presupuestos de hecho y normativos para la procedencia del amparo constitucional. Consecuencia de lo mismo, la Corte IDH dictó una sentencia paradigmática que en gran medida aborda la cuestión aquí tratada del derecho humano a la identidad cultural. Con todo, se trata de una sentencia de 2020, que obliga a adoptar medidas efectivas de cumplimiento en un plazo de 6 años, dado lo cual la comunicación entre los órganos jurisdiccionales interamericano y nacional no está cerrada.

En el segundo caso (Chile) de data algo distante (2004-2014), también la judicatura nacional actúa inicialmente en violación del derecho humano a la identidad cultural. Luego, la Corte IDH establece la vulneración del derecho y condena, con expreso reconocimiento del derecho humano a la identidad cultural. Pero, finalmente, es la propia jurisdicción nacional la que, dando cumplimiento a la decisión interamericana, avanza en la perspectiva dialógica haciendo suya la fundamentación de la Corte IDH e involucrando al juez nacional como "órgano interamericano" responsable de la tutela de la CADH, ergo, del derecho humano a la identidad cultural. Además, describe su propia función bajo un doble aspecto: (i) de respeto y garantía; y (ii) como hermeneuta interamericano.

Finalmente, en el tercer caso de Brasil (2021), el órgano jurisdiccional nacional, fundado en las obligaciones constitucionales, expresa una argumentación que dialoga armónicamente con los estándares interamericanos. Incluso, desarrolla una comprensión del derecho humano a la identidad cultural que expresa la comprensión amplia de este derecho, en su sentido más robusto asociado al derecho a la vida (como sobrevivencia de los pueblos indígenas y otros grupos tradicionales), pero también como DESC, vinculado a la obligación de satisfacer las acciones prestacionales de salud requeridas, con adecuación a las condiciones sociales y culturales propias de los pueblos afectados. 
Así, hemos podido observar que el diálogo judicial en torno a un derecho común interamericano de derechos humanos, debiera entenderse de forma dúctil a la multiplicidad de escenarios sociales, culturales y normativos en que se requiere el amparo de los respectivos derechos humanos, en la media que la acción e interacción jurisdiccional -internacional y nacional(es)-, a la luz de tal derecho común, logra/ $n$ su objetivo tutelar de los grupos vulnerables y, así, efectivamente se constituyen en un pilar de la democracia en América Latina, al asegurar la diversidad como elemento constitutivo de ella. Y, del mismo modo, se refuerza la concepción del Estado de Derecho como soporte de la democracia, pero como un orden normativo esencialmente tutelar de los derechos humanos.

\section{Referencias}

AGUILAR, Gonzalo (coord.). Derechos económicos, sociales y culturales en el Orden Constitucional Chileno. Santiago: Editorial Librotecnia, 2012.

AGUILAR, Gonzalo. Emergencia de un derecho constitucional común en materia de pueblos indígenas. En: BOGDANDY, Armin von; FERRER MAC-GREGOR, Eduardo, MORALES-ANZIONATTI, Mariela. (coord.), La justicia constitucional y su internacionalización. ¿Hacia un Ius Constitucionale Commune en América Latina? Tomo II. México: UNAM, MPI, IIADC. 2010. p. 3-84.

ALBANESE, Susana (coord.). El control de convencionalidad. Buenos Aires: Ediciones Ediar, 2008.

AYLWIN, José; MEZA-LOPEHANDÍA, Matías; YAÑEZ, Nancy. Los pueblos indígenas y el derecho. Santiago: LOM, 2013.

BÁEZ, N. Lima. La protección de la identidad cultural de los pueblos indígenas a través del derecho a la integridad personal. Revista electrónica methodos, n. 1, p. 23-45, 2011.

Barroso, Luis Roberto. Curso de Direito Constitucional Contempoâneo. Os conceitos fundamentais e a contruçã de novo modelo. Sao Paulo: Saraiva, 2019.

BOGDANDY, Armin von. Ius Constitucionale Commune na América Latina: uma reflexão sobre um Constitucionalismo Transformador. Revista de Direito Administrativo, Rio de janeiro, v. 269, maio/ago. 2015.

BRASIL. Supremo Tribunal Federal. Arguição de Descumprimento de Preceito Fundamental n. 709. Relator: Ministro Luís Roberto Barroso, j. 05 de agosto de 2020

BURGORGUE-LARSEN, Laurence. La Corte Interamericana de los Derechos Humanos como Tribunal constitucional. Em: MAUÉS, Antonio Moreira, MAGALHÃES, Breno Baía (org.). O controle de convencionalidade na América Latina: experiências comparadas. Rio de Janeiro: Lumen Juris, 2018. p. 1-35.

CALDERÓN, Jorge. Avances, aproximaciones y desafíos emergentes en el reconocimiento de los derechos colectivos de los pueblos indígenas y tribales en la jurisprudencia de la Corte Interamericana de Derechos Humano. En: BOGDANDY, Armin von; MORALES, Mariela; FERRER MAC-GREGOR, Eduardo (Edts.). Construcción de un ius constitucionale commune en América Latina. México: UNAM, MPI, Corte IDH, 2016. pp. 95-113.

CORTE IDH. Caso Comunidad indígena Xákmok Kásek Vs. Paraguay, sentencia de 24 agosto 2010. (Fondo, Reparaciones y Costas).

CORTE IDH. Caso Comunidad Indígena Yakye Axa Vs. Paraguay, Sentencia de 17 de junio de 2005 (Fondo, Reparaciones y Costas).

CORTE IDH. Caso de la Comunidad Indígena Sawhoyamaxa Vs. Paraguay, sentencia de 29 de marzo 2006. (Fondo, Reparaciones y Costas). 
CORTE IDH. Caso del Pueblo Xucuro Vs. Brasil, sentencia de 5 de febrero de 2018 (Excepciones Preliminares, Fondo, Reparaciones y Costas).

CORTE IDH. Caso Pueblo Indígena Kichwa de Sarayaku Vs. Ecuador, sentencia de 12 junio 2012 (Fondo y Reparaciones).

CORTE IDH. Caso Pueblo Saramaka vs. Surinam, sentencia de 28 de noviembre de 2007 (Excepciones Preliminares, Fondo, Reparaciones y Costas).

CORTE SUPREMA DE JUSTICIA DE LA NACIÓN DE ARGENTINA -CSJN-. A. 1596, XLI. Acción declarativa de inconstitucionalidad, Asociación Lhaka Honhat contra Provincia de Salta y otros. Acción declarativa de certeza, sentencia de 27 de septiembre de 2005.

DEL CARPIO RODRÍGUEZ, Columba. Pluralismo jurídico. Derecho humano a la identidad cultural y globalización. Pamplona: CIVITAS, Thomson Reuters, 2014.

ESTUPIÑAN, Rosmelin; IBÁÑEZ, Juana María. La jurisprudencia de la Corte Interamericana de Derechos Humanos en materia de pueblos indígenas y tribales. París: Universidad de París. Grupo de Estudios en Derecho Internacional y Latinoamericano de la Sorbona. 2014.

FAUNDES, Juan Jorge, RAMÍREZ, Silvina (ed.). Derecho fundamental a la identidad cultural, abordajes plurales desde América Latina. Santiago: RIL, Universidad Autónoma de Chile, 2020.

Faundes, Juan Jorge. El derecho fundamental a la identidad cultural de los pueblos indígenas: un derecho matriz y filtro hermenéutico para las constituciones de América Latina: la justificación. Revista Brasileira Politicas Públicas, Brasília, v. 9 n. 2, 2019.

FAUNDES, Juan Jorge. Interpretación evolutiva de los derechos humanos. En: ÁLVAREZ, Mario; CIPPITANI, Roberto (coord.). Diccionario Analitico de Derechos Humanos e Integración Jurídica. Roma, Perugia, México: ISEG. 2013. p. 325-332.

FAUNDES, Juan Jorge; CARMONA, Cristobal; SILVA, Pedro Pablo. La Corte Interamericana de Derechos Humanos. Hermenéutica del derecho al medio ambiente sano, a la identidad cultural y a la consulta, a la luz de la sentencia "Lhaka Honhat (nuestra tierra) vs. Argentina". Revista Brasileira de Políticas Públicas, Brasília, v. 10, n. 2, p. 635-666, 2020.

FAUNDES, Juan Jorge; VALLEJOS, Liz. El derecho fundamental a la identidad cultural de los pueblos indígenas, titulares, naturaleza, contenido y alcances, desde la jurisprudencia de la Corte Interamericana de Derechos Humanos. Em: FAUNDES Juan Jorge; RAMÍREZ Silvina (ed.). Derecho fundamental a la identidad cultural, abordajes plurales desde América Latina. Santiago: RIL, Universidad Autónoma de Chile, 2020. p. 107144.

FERRER MAC-GREGOR, Eduardo. Control de convencionalidad y buenas prácticas: sobre el diálogo judicial entre la Corte IDH y los tribunales nacionales. En: UGARTEMENDIA, Juan Ignacio; SAIZ, Alejandro; MORALES, Mariela. La jurisdicción constitucional en la tutela de los Derechos Fundamentales de la UE. Oñati: IVAP, MPI. 2017, p. 155-174.

FERRER MAC-GREGOR, Eduardo. Diálogo judicial y control convencionalidad: aportes de la Corte Interamericana en la construcción de un IUS Constitucionale Commune Para América Latina (ICCAL). En: FERRER MAC-GREGOR, Eduardo (coord.). Derecho procesal constitucional transnacional. Interacción entre el derecho nacional y el derecho internacional. México: Editorial Porrúa, IMDPC. 2016. p. 277-294.

FERRER MAC-GREGOR, Eduardo. Interpretación conforme y control difuso de convencionalidad el nuevo paradigma para el juez mexicano. En: CARBONELL, Miguel, SALAZAR, Pedro. Derechos Humanos: Un nuevo modelo constitucional. México: UNAM-IIJ, 2011. p. 339-429.

HENRÍQUEZ, Miriam; MORALES, Mariela. El control de convencionalidad: un balance comparado a 10 Años 
de Almonacid Arellano vs. Chile. Santiago: DER Ediciones. 2017.

KLARE, Karl E. Legal culture and transformative constitutionalism. South African Journal on Human Rights, v. 14, n. 1, p. 146-188, p. 150, jan. 1998.

LEGALE, Siddharta. La Constitución Interamericana: Los 50 Años de la Convención Americana sobre Derechos Humanos en la Jurisprudencia de la Corte Interamericana de Derechos Humanos. En: COMITÉ Jurídico Interamericano Curso de Derecho Internacional XLVI 2019. Rio de Janeiro: Comité Jurídico Interamericano y el Departamento de Derecho Internacional de la Secretaría de Asuntos Jurídicos de la Organización de los Estados Americanos. 2019.

MELLO, Patricia Perrone Campos. Constitucionalismo, Transformação e Resiliência Democrática no Brasil: o Ius Constitucionale Commune na América Latina tem uma contribuição a oferecer?. Revista Brasileira Políticas Públicas, Brasília, v. 9 n. 2. 2019.

MELLO, Patricia Perrone Campos; ACCIOLY, Clara Lacerda. El derecho fundamental a la identidad cultural y el constitucionalismo en red en la jurisprudencia del Supremo Tribunal Federal de Brasil. En: FAUNDES, Juan Jorge; RAMÍREZ, Silvina (ed.). Derecho fundamental a la identidad cultural, abordajes plurales desde América Latina. Santiago: RIL, Universidad Autónoma de Chile, 2020. p. 197-230.

MELLO, Patricia Perrone Campos; FAUNDES, Juan Jorge. Constitucionalismo em rede: o direito à identidade cultural dos povos indígenas como filtro hermenêutico para tutela da tradicionalidade da ocupação da terra. En: Rossito, Flávia Donini et. al. Quilombolas e outros povos tradicionais. Curitiba: CEPEDIS, 2020. p. 317-339.

MELLO, Patrícia Perrone Campos; FAUNDES, Juan Jorge. Povos Indígenas e proteção da natureza: a caminho de um "giro hermenêutico ecocêntrico". Revista Brasileira de Políticas Públicas, Brasília, v. 10, n. 3, p. 222-251, 2020.

MORALES, Mariela. El estado abierto como objetivo del ius constitucionale commune. Aproximación desde el impacto de la Corte Interamericana de Derechos Humanos. En: BOGDANDY, Armin von, FIX-FIERRO, Héctor, MORALES, Mariela (ed.). Ius constitucionale comune en América Latina. Rasgos, potencialidades y desafíos. México: UNAM, MPI, IIDC, 2014. p. 265-299.

MORALES, Mariela. La vulnerabilidad como principio transnacional. Aportes de la CORTE IDH a la luz del IUS CONSTITUCIONALE COMMUNE democrático. En: FERRER MAC-GREGOR, Eduardo (coord.). Derecho procesal constitucional transnacional. Interacción entre el derecho nacional y el derecho internacional. México: Editorial Porrúa, IMDPC, 2016. p. 295-334.

NASH, Claudio. La Concepción de Derechos Fundamentales en Latinoamérica. Tendencias jurisprudenciales. Tesis (Doctorado). Universidad de Chile, Santiago, 2008.

OLIVARES, Alberto. El Derecho a la identidad cultural. En: AGUILAR, Gonzalo (coord.). Nuevos derechos para una nueva Constitución. Valencia: Tirant Lo Blanch. 2019. p, 175-190.

RUIZ CHIRIBOGA, Oswaldo. El derecho a la identidad cultural de los pueblos indígenas y las minorías nacionales: una mirada desde el sistema interamericano. Revista Internacional de Derechos Humanos, v. 5, n. 3, p. 43-69, 2006.

SARLET, Ingo; FIGUEIREDO, Mariana Filchtiner. Reserva do possível, mínimo existencial e direito à saúde. Revista de Direitos Fundamentais \& Justiça, v.1, n.1, p. 171-213, out./dez. 2007.

SARMENTO, Daniel. Direitos Fundamentais e Relações Privadas. 2. ed. Rio de Janeiro: Editora Lumen Juris, 2010.

SCHIER, P. Filtragem Constitucional. Porto Alegre: Sergio Antonio Fabris, 1999.

TORRES, Ricardo Lobo. A metamorfose do direitos sociais em mínimo existencial. In: SARLET, Ingo 
Wolfgang (org.). Direitos fundamentais sociais: estudos de direitos constitucional, internacional e comparado. Rio de Janeiro: Renovar, 2003.

TORRES, Ricardo Lobo. O direito ao mínimo existencial. Rio de Janeiro: Renovar, 2009.

VARELLA, Marcelo; MONEBHUURRUN, Nitish; GONTIJO, André Pires. Protẹça internacional dos direitos bumanos. Rio de Janeiro: Editora Processo, 2019.

VOLPINI, Carla Ribeiro; WANDERLEY JUNIOR, Silva Bruno. A responsabilidade internacional do Brasil em face do controle de convencionalidade em sede de direitos humanos: conflito de interpretação entre a jurisdição da Corte Interamericana de Direitos Humanos e o Supremo Tribunal Federal quanto a Lei de anistia. Brazilian Journal of International Law, v. 12 n. 2, p. 611-629. 2015.

ZIMERMAN, Silvina. Estándares internacionales de derechos humanos sobre el derecho indígena a la tierra y al territorio: un estudio sobre su contenido normativo y sobre el desarrollo de pautas para la creación de garantías de protección. 2014. Tesis (Doctoral). Universidad de Buenos Aires, Buenos Aires, 2014. 
Para publicar na revista Brasileira de Políticas Públicas, acesse o endereço eletrônico www.rbpp.uniceub.br

Observe as normas de publicação, para facilitar e agilizar o trabalho de edição. 